\title{
Mixing layer height and its implications for air pollution over Beijing, China
}

\author{
Guiqian Tang ${ }^{1}$, Jinqiang Zhang ${ }^{2}$, Xiaowan Zhu ${ }^{1}$, Tao Song ${ }^{1}$, Christoph Münkel ${ }^{3}$, Bo Hu ${ }^{1}$, Klaus Schäfer ${ }^{4}$, Zirui Liu ${ }^{1}$, \\ Junke Zhang ${ }^{1}$, Lili Wang ${ }^{1}$, Jinyuan Xin ${ }^{1}$, Peter Suppan ${ }^{4}$, and Yuesi Wang ${ }^{1}$ \\ ${ }^{1}$ State Key Laboratory of Atmospheric Boundary Layer Physics and Atmospheric Chemistry (LAPC), \\ Institute of Atmospheric Physics, Chinese Academy of Sciences, Beijing 100029, China \\ ${ }^{2}$ Key Laboratory of Middle Atmosphere and Global Environment Observation (LAGEO), Institute of Atmospheric Physics, \\ Chinese Academy of Sciences, Beijing 100029, China \\ ${ }^{3}$ Vaisala GmbH, 22607 Hamburg, Germany \\ ${ }^{4}$ Karlsruhe Institute of Technology (KIT), Institute of Meteorology and Climate Research, Atmospheric Environmental \\ Research (IMK-IFU), 82467 Garmisch-Partenkirchen, Germany
}

Correspondence to: Yuesi Wang (wys@mail.iap.ac.cn)

Received: 3 September 2015 - Published in Atmos. Chem. Phys. Discuss.: 21 October 2015

Revised: 30 January 2016 - Accepted: 17 February 2016 - Published: 1 March 2016

\begin{abstract}
The mixing layer is an important meteorological factor that affects air pollution. In this study, the atmospheric mixing layer height (MLH) was observed in Beijing from July 2009 to December 2012 using a ceilometer. By comparison with radiosonde data, we found that the ceilometer underestimates the MLH under conditions of neutral stratification caused by strong winds, whereas it overestimates the MLH when sand-dust is crossing. Using meteorological, $\mathrm{PM}_{2.5}$, and $\mathrm{PM}_{10}$ observational data, we screened the observed MLH automatically; the ceilometer observations were fairly consistent with the radiosondes, with a correlation coefficient greater than 0.9. Further analysis indicated that the MLH is low in autumn and winter and high in spring and summer in Beijing. There is a significant correlation between the sensible heat flux and MLH, and the diurnal cycle of the MLH in summer is also affected by the circulation of mountainous plain winds. Using visibility as an index to classify the degree of air pollution, we found that the variation in the sensible heat and buoyancy term in turbulent kinetic energy (TKE) is insignificant when visibility decreases from 10 to $5 \mathrm{~km}$, but the reduction of shear term in TKE is near $70 \%$. When visibility decreases from 5 to $1 \mathrm{~km}$, the variation of the shear term in TKE is insignificant, but the decrease in the sensible heat and buoyancy term in TKE is approximately $60 \%$. Although the correlation between the daily variation of the MLH and visibility is very poor, the
\end{abstract}

correlation between them is significantly enhanced when the relative humidity increases beyond $80 \%$. This indicates that humidity-related physicochemical processes is the primary source of atmospheric particles under heavy pollution and that the dissipation of atmospheric particles mainly depends on the MLH. The presented results of the atmospheric mixing layer provide useful empirical information for improving meteorological and atmospheric chemistry models and the forecasting and warning of air pollution.

\section{Introduction}

The mixing layer is formed when discontinuous turbulence exists due to discontinuities in temperature stratification between the upper and lower layers of the atmosphere. The atmospheric mixing layer height (MLH) is an important meteorological factor that affects the vertical diffusion of atmospheric pollutants and water vapour concentrations; therefore, it impacts the formation and dissipation of air pollutants (Aron, 1983; Stull, 1988). Continuous observations of the MLH are helpful for improving the parameterizations of boundary layer models, and they play an important role of improving the simulation accuracy of meteorological models and optimizing the simulation results for pollutants. 
Three primary observation methods are used to determine the MLH: meteorological radiosondes, aeroplane surveys, and ground-based remote sensing. As the most conventional observation approach, meteorological radiosonde profiles utilize a large number of observation stations distributed globally and provide high-quality data. However, because of the high cost of the observation, only two observations at 00:00 and 12:00 UTC are available from most stations (Seibert et al., 2000). When solar radiation increases in the morning, the growth rate of the MLH reaches hundreds of metres per hour and convection develops quickly; even if hourly observations were available, they could not provide sufficient temporal resolution of the evolution of MLH (Seibert et al., 2000). Although aeroplane surveys can be used to obtain high-resolution meteorological and pollutant profiles, the constraints of air traffic control, weather conditions, and observation costs limit these data to short time periods. Therefore, to acquire continuous observations with high spatial and temporal resolution, ground-based remote sensing has become the most advanced approach to MLH measurement.

Acoustic radar (sodar), laser radar (lidar) and electromagnetic radar (Doppler radar) are the three methods used to perform ground-based remote sensing. Sodar can obtain the vertical profiles of wind and temperature, and these can be used to calculate the MLH. Doppler wind radar can obtain variations of the wind vectors at different altitudes and identify the mixing layer through wind shear. Lidar can obtain the vertical profile of the aerosol concentration and discern the atmospheric MLH by calculating the height at which sudden changes in the profile occur.

Beyrich (1997), Seibert et al. (2000), and Emeis et al. (2008) conducted reviews of these three methods, comparing their advantages and disadvantages. The sodar detection height is usually less than $1000 \mathrm{~m}$, which is not conducive for observing the MLH under convection states. The lowest detection height of wind radar is normally above $200 \mathrm{~m}$, and the vertical resolution is limited to $50-250 \mathrm{~m}$, factors that make the interpretation of wind radar data not always straightforward (Seibert et al., 2000). Prior to the application of modern laser ceilometers, lidar was costly and not widely used. In recent years, lidar observation technology has developed rapidly, and an increasing number of applications have used lidar for MLH observations (White et al., 1999; Steyn et al., 1999; Hägeli et al., 2000; Chen et al., 2001; Schneider and Eixmann, 2002; Kunz et al., 2002; Strawbridge and Snyder, 2004; He et al., 2006; Wiegner et al., 2006; Sicard et al., 2006; Hennemuth and Lammert, 2006; Emeis et al., 2007; Wang et al., 2012; Yang et al., 2013; Luo et al., 2014; Scarino et al., 2014). Meanwhile, eye-safe ceilometers that permit observation of the MLH with a nearinfrared band laser have been developed. Due to their simple operation and low cost, these instruments have become the optimal method for MLH observation, and they have been widely used in recent years (Münkel and Räsänen, 2004;
Emeis et al., 2004, 2012; Emeis and Schäfer, 2006; Eresmaa et al., 2006; Münkel et al., 2007; McKendry et al., 2009; Kamp and McKendry, 2010; Muňoz and Undurraga, 2010; Flentje et al., 2010; Chen et al., 2011; Haeffelin et al., 2012; Pappalardo et al., 2014; Wiegner et al., 2014; Schween et al., 2014; Sicard et al., 2015; Tang et al., 2015).

Beijing, located on the North China Plain, is the centre of politics, culture, and economics in China. With the rapid development of the economy and the concomitant increase in energy usage, serious air pollution and heavy haze occurs frequently (Tang et al., 2009, 2012, 2015; Xin et al., 2010; Wang et al., 2014; Zhang et al., 2014; Yang et al., 2015). Previous studies of Beijing have indicated that visibility declines dramatically when the concentration of particles increases; the weather conditions typically include high relative humidity (RH), stable atmospheric stratification, and low wind speed (WS) with southerly flow during the polluted period (Ding et al., 2005; Liu et al., 2014; Zhang et al., 2015).

Although many studies have provided detailed descriptions of other weather conditions during heavy pollution periods, variations in atmospheric MLH are not well understood. As a key meteorological factor, MLH has a strong influence on the occurrence, maintenance, and dissipation of heavy pollution. For most areas in northern China, the meteorological radiosondes can only acquire the MLH in the morning (08:00 LT) and at night (20:00 LT), so observations of the convective mixing layer at noon are lacking. In certain studies, simulations with numerical models, short-time groundbased remote sensing, or meteorological profiles are used to provide a preliminary description of MLH during heavy pollution periods (He and Mao, 2005; Yang et al., 2005; Zhang et al., 2006; Chen et al., 2009; Quan et al., 2013; Hu et al., 2014; Zhang et al., 2015), but continuous high-resolution observations over a long time period have not been conducted for this region. Without the continuous high-resolution characteristics of MLH, its impact on air pollution cannot be studied thoroughly (Schäfer et al., 2006).

To compensate for the deficiencies in the aforementioned studies, a ceilometer was used to conduct continuous high-resolution observations for 3 years and 6 months (from July 2009 to December 2012) in Beijing. By comparing the obtained data with multiple meteorological and pollutant data sets, we verified the applicability of the ceilometer and obtained the temporal variations of the MLH over 3 years. By combining the meteorological data, we were able to determine the variations of the mixing layer and the atmospheric diffusion capability in different seasons. Finally, we used visibility as an index to classify the degree of air pollution, and analysed the thermal/dynamic parameters inside the mixing layer under different degrees of pollution; then, we delineated the influence of MLH on air pollution and revealed the critical meteorological factors that affect the formation and dissipation of heavy air pollution in Beijing. 
Table 1. Site description and instrument list. BJT refers to the Beijing tower; ZBAA is the international standard weather station.

\begin{tabular}{|c|c|c|c|c|}
\hline Sites & Long, lat & Instruments & Time interval & Time resolution \\
\hline \multirow[t]{4}{*}{ BJT } & $116.372,39.974$ & CL31 & 15 Jul 2009-16 Dec 2012 & $10 \mathrm{~min}$ \\
\hline & & $\mathrm{PM}_{2.5}, \mathrm{PM}_{10}$ & 15 Jul 2009-31 Dec 2012 & $60 \mathrm{~min}$ \\
\hline & & Tower-based meteorology & 15 Jul 2009-31 Dec 2012 & $30 \mathrm{~min}$ \\
\hline & & Chemical compositions in $\mathrm{PM}_{1}$ & 24 Nov 2010-31 Dec 2012 & $60 \mathrm{~min}$ \\
\hline \multirow[t]{3}{*}{ ZBAA } & $116.282,39.484$ & Weather balloons & 15 Jul 2009-31 Dec 2012 & 1 per week at 14:00 LT \\
\hline & & Weather balloons & 1 Jan 2012-31 Dec 2012 & 08:00 and 20:00 LT \\
\hline & & Ground-based meteorology & 15 Jul 2009-31 Dec 2012 & $30 \mathrm{~min}$ \\
\hline
\end{tabular}

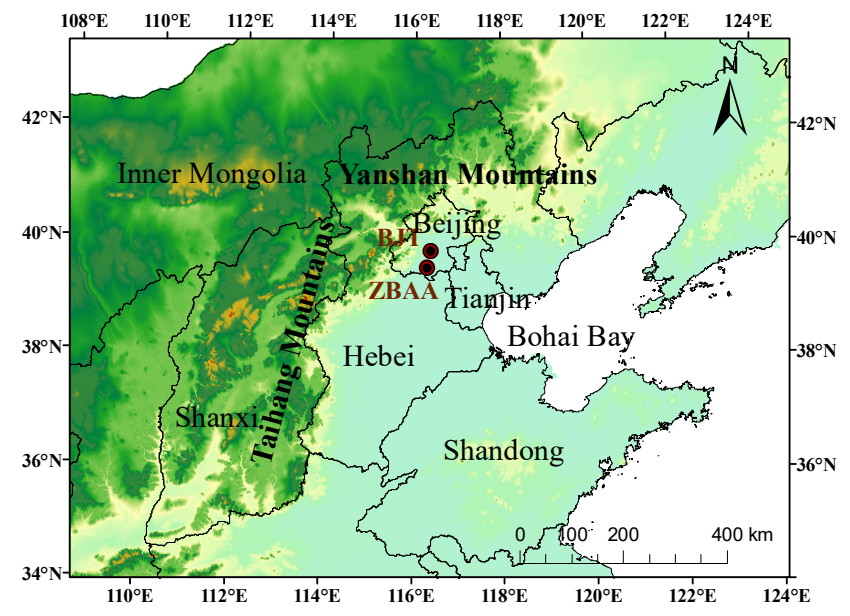

Figure 1. Topography and the observation sites.

\section{Methods}

\subsection{Sites and instruments}

To understand the characteristics of the mixing layer in the Beijing area, we conducted observations for 3 years and 6 months (from 15 July 2009 to 16 December 2012) in Beijing. The observation sites, parameters, and time periods are shown in Fig. 1 and Table 1.

\subsubsection{BJT site}

The site used to measure the MLH was built in the courtyard of the Institute of Atmospheric Physics, Chinese Academy of Sciences, to the west of the Jiande bridge in the Haidian district, Beijing (ID: BJT). This site is located between the north third and the north fourth ring road, and the Beijing-Tibet motorway is on the eastern side. The geographic location of the station is $39.974^{\circ} \mathrm{N}, 116.372^{\circ} \mathrm{E}$, and the elevation (a.s.l.) is approximately $60 \mathrm{~m}$.

The instrument used to observe the MLH was a single-lens ceilometer (CL31, Vaisala, Finland). This instrument utilizes pulsed diode laser lidar technology (910 $\mathrm{nm}$ waveband) to measure the attenuated backscatter coefficient profile and then determine the MLH. For practical measurements, the time resolution was set to $16 \mathrm{~s}$, the vertical resolution was set to $10 \mathrm{~m}$, and the measurement range was $7.7 \mathrm{~km}$. Because the atmospheric aerosol concentration is relatively high in Beijing, the CL31 lens was cleaned with clear water every 3 days.

The conventional meteorological data during the same period included temperature, $\mathrm{RH}, \mathrm{WS}$, and wind direction observations at $8,15,32,47,65,80,100,120,140,160,180$, $200,240,280$, and $320 \mathrm{~m}$ along the tower in a vertical direction, and the temporal resolution was $30 \mathrm{~min}$. The detailed description is provided by Song et al. (2013). The thermodynamic parameters (sensible heat, latent heat, friction velocity, etc.) and the total $(285-2800 \mathrm{~nm})$ and net $(0.2-100 \mu \mathrm{m})$ radiation during the same period were observed using ultrasonic anemometers (CSAT3, Campbell Scientific, USA), a pyranometer (CM11, Kipp \& Zonen, Netherlands) and a net radiometer (NR Lite2, Kipp \& Zonen, Netherlands), respectively. All of these data were obtained on the meteorological tower at a height of $280 \mathrm{~m}$ and processed with a resolution of $30 \mathrm{~min}$. The detailed description is provided by $\mathrm{Hu}$ et al. (2012) and Song and Wang (2012). The sensible heat $\left(Q_{\mathrm{H}}\right)$, latent heat $\left(Q_{\mathrm{E}}\right)$, friction velocity $\left(u_{*}\right)$, and turbulence kinetic energy (TKE) were calculated as follows (Stull, 1988; Garratt, 1992):

$$
\begin{aligned}
& Q_{\mathrm{H}}=\rho c_{p} \overline{w^{\prime} \theta_{\mathrm{v}}^{\prime}} \\
& Q_{\mathrm{E}}=L_{\mathrm{v}} \overline{w^{\prime} q^{\prime}} \\
& u_{*}=\left(\overline{u^{\prime} w^{\prime}}+\overline{v^{\prime} w^{\prime}}\right)^{1 / 4} \\
& \frac{\mathrm{TKE}}{m}=\frac{1}{2}\left(\overline{u^{\prime 2}}+\overline{v^{\prime 2}}+\overline{w^{\prime 2}}\right)=\bar{e},
\end{aligned}
$$

where $\rho$ is the air density $\left(\mathrm{kg} \mathrm{m}^{-3}\right), c_{p}$ is the specific heat capacity for air at constant pressure $\left(\mathrm{J} \mathrm{kg}^{-1} \mathrm{~K}^{-1}\right), \theta_{\mathrm{v}}$ is the virtual potential temperature $(\mathrm{K}), L_{\mathrm{V}}$ is the latent heat of vaporization of water $\left(\mathrm{J} \mathrm{kg}^{-1}\right), q$ is the water vapour density $\left(\mathrm{kg} \mathrm{m}^{-3}\right), m$ is the mass $(\mathrm{kg}), \bar{e}$ is the TKE per unit mass $\left(\mathrm{m}^{2} \mathrm{~s}^{-1}\right)$, and $u, v$, and $w$ are the streamwise, cross-stream and vertical wind velocities $\left(\mathrm{m} \mathrm{s}^{-1}\right)$, respectively.

To identify the sand-dust crossing, the ratio of $\mathrm{PM}_{2.5}$ to $\mathrm{PM}_{10}$ was used as an index. If there was no sand-dust crossing, the ratio of $\mathrm{PM}_{2.5}$ to $\mathrm{PM}_{10}$ might almost exceed $50 \%$ (Liu et al., 2014). A sudden decrease in the ratio to $30 \%$ or 
lower and $\mathrm{PM}_{10}$ concentration higher than $500 \mu \mathrm{g} \mathrm{m}^{-3}$ usually indicate a sand-dust crossing. The ground observations of $\mathrm{PM}_{2.5}$ and $\mathrm{PM}_{10}$ during the same period were made by the ambient particulate monitor (RP1400a, Thermo Fisher Scientific, USA). The data were acquired at a time resolution of $5 \mathrm{~min}$ and processed with a resolution of $60 \mathrm{~min}$. A detailed description is provided by Liu et al. (2014).

To illustrate the variations of the chemical compositions in particles, the ground-based observations of organic matters $(\mathrm{OM})$, sulphate $\left(\mathrm{SO}_{4}^{2+}\right)$, nitrate $\left(\mathrm{NO}_{3}^{-}\right)$, ammonium $\left(\mathrm{NH}_{4}^{+}\right)$and chloride $\left(\mathrm{Cl}^{-}\right)$in $\mathrm{PM}_{1}$ were observed by a highresolution time-of-flight aerosol mass spectrometer (Aerodyne Research Inc., USA). The data were acquired at a time resolution of $5 \mathrm{~min}$ and processed with a resolution of $60 \mathrm{~min}$. A detailed description has been reported elsewhere (Zhang et al., 2014).

\subsubsection{ZBAA site}

The meteorological radiosondes were measured by the international standard weather station (ID: ZBAA) that is located outside the south second ring road in the Fengtai district, Beijing, $10 \mathrm{~km}$ from the BJT site. The geographic position of station ZBAA is $39.484^{\circ} \mathrm{N}$ and $116.282^{\circ} \mathrm{E}$, and the elevation (a.s.l.) is approximately $34 \mathrm{~m}$.

The meteorological radiosondes observed at station ZBAA included two categories: conventional observations, which were conducted at 08:00 LT in the morning and at 20:00 LT in the evening each day; and intensified observations, which were conducted at 14:00 LT in the afternoon every Thursday. The observed meteorological parameters included atmospheric pressure, temperature, $\mathrm{RH}, \mathrm{WS}$, wind direction, and ozone. In this study, the methods of Eresmaa et al. (2006) and Münkel et al. (2007) were used to divide the radiosondes into stable and convective states according to the atmospheric stratification status. The meteorological radiosondes were defined as encountering a convective state when they exhibited negative lapse rates for the $\theta_{\mathrm{v}}$ within $200 \mathrm{~m}$ and bulk Richardson numbers $\left(R_{\mathrm{B}}\right)$ within $100 \mathrm{~m}$, and other profiles were defined as a stable state. In this project, the $R_{B}$ was determined by the formula of Stull (1988), as follows:

$R_{\mathrm{B}}=\frac{g \Delta \theta_{\mathrm{v}} \Delta z}{\theta_{\mathrm{v}}\left((\Delta u)^{2}+(\Delta v)^{2}\right)}$,

where $g$ is the acceleration of gravity $\left(\mathrm{m} \mathrm{s}^{-2}\right)$, and $z$ is the height $(\mathrm{m})$.

PM concentration proved to be a good indicator for characterization of the degree of air pollution. However, haze was defined by the visibility in China as shown in Table 2 (CMA, 2010), and it was remarkably negatively correlated with PM concentration (Yang et al., 2015). Because PM data were occasionally missing, visibility was used as an index to classify the degree of air pollution. Visibility at station ZBAA, which was obtained from the Department of Atmospheric Science, College of Engineering, University of Wyoming (http://weather.uwyo.edu/surface/meteorogram/), was measured by a visibility sensor (PWD12, Vaisala, Finland) with an accuracy of $\pm 10 \%$.

\subsection{Determination of the MLH}

\subsubsection{MLH retrieval by ceilometer}

Because the lifetime of particles can be several days or even weeks, the distribution of particle concentrations in the MLH is more uniform than that of gaseous pollutants. However, the particle concentration in the mixing layer and that in the free atmosphere are significantly different. In the attenuated backscatter coefficient profile, the position at which a sudden change occurs in the profile indicates the top of the atmospheric mixing layer. In this study, we used the Vaisala software product BL-VIEW to determine the MLH by selecting the location with the maximum negative gradient $(-\mathrm{d} \beta / \mathrm{d} x)$ in the attenuated backscatter coefficient profile as the top of the mixing layer (Steyn, et al., 1999; Münkel et al., 2007). To eliminate the influence of inherent noise and aerosol layers on the data, spatial and temporal averaging must be carried out before the gradient method is used to calculate the MLH (Münkel et al., 2007; Tang et al., 2015). Time averaging is dependent on the current signal noise; the intervals vary from 14 to $52 \mathrm{~min}$ for the CL31. Height averaging intervals range from $80 \mathrm{~m}$ at ground level to $360 \mathrm{~m}$ at $1600 \mathrm{~m}$ height and beyond. Additional features of this algorithm, which is used in the Vaisala software product BL-VIEW, are cloud and precipitation filtering and outlier removal.

\subsubsection{MLH retrieval by radiosonde}

A number of methods have been developed for analysis of the mixing layer through the meteorological radiosonde (Beyrich, 1997; Seibert et al., 2000; Wang and Wang, 2014). In this study, we calculated the MLH for the convective and stable states, respectively. For the convective state, we used the Holzworth method (Holzworth, 1964, 1967), which is the method most widely applied to obtain the MLH by analysing profiles in the $\theta_{\mathrm{v}}$. In a stable state, a low-level jet often occurs in Beijing, and we can determine the MLH by analysing the position of the low-level jet (Devara et al., 1995; Tang et al., 2015). If the low-level jet does not exist under stable weather conditions, the altitude at which the $R_{\mathrm{B}}$ is greater than 1 is the MLH (Vogelezang and Holtslag, 1996; Eresmaa et al., 2006).

\section{Results and discussions}

\subsection{Verification of the MLH}

Previous studies with ceilometers did not resolve issues concerning the applicability of ceilometers in Chinese areas with high aerosol concentrations. According to the methods de- 
Table 2. Statistics of the thermal/dynamic parameters under different degrees of air pollution.

\begin{tabular}{|c|c|c|c|c|c|}
\hline Parameters & $\begin{array}{r}\text { Clear days } \\
\text { Vis } \geq 10 \mathrm{~km}\end{array}$ & $\begin{array}{r}\text { Slight haze } \\
5 \mathrm{~km} \leq \text { Vis }<10 \mathrm{~km}\end{array}$ & $\begin{array}{r}\text { Light haze } \\
3 \mathrm{~km} \leq \mathrm{Vis}<5 \mathrm{~km}\end{array}$ & $\begin{array}{r}\text { Medium haze } \\
2 \mathrm{~km} \leq \mathrm{Vis}<3 \mathrm{~km}\end{array}$ & $\begin{array}{r}\text { Heavy haze } \\
\text { Vis }<2 \mathrm{~km}\end{array}$ \\
\hline $\mathrm{WS}\left(\mathrm{ms}^{-1}\right)$ & 3.8 & 2.5 & 2.1 & 2.0 & 1.8 \\
\hline $\mathrm{RH}(\%)$ & 43.3 & 63.1 & 73.4 & 79.6 & 86.4 \\
\hline MLH (m) & 664 & 671 & 586 & 430 & 320 \\
\hline$Q^{*}\left(\mathrm{~W} \mathrm{~m}^{-2}\right)$ & 77.6 & 74.6 & 63.9 & 53.6 & 32.8 \\
\hline$Q_{\mathrm{H}}\left(\mathrm{Wm}^{-2}\right)$ & 20.4 & 19.7 & 15.2 & 12.8 & 7.8 \\
\hline$Q_{\mathrm{E}}\left(\mathrm{W} \mathrm{m}^{-2}\right)$ & 18.7 & 19.9 & 21.5 & 18.8 & 19.8 \\
\hline$u_{*}\left(\mathrm{~m} \mathrm{~s}^{-1}\right)$ & 0.45 & 0.32 & 0.28 & 0.26 & 0.23 \\
\hline $\bar{e}\left(\mathrm{~m}^{2} \mathrm{~s}^{-2}\right)$ & 0.99 & 0.64 & 0.56 & 0.52 & 0.46 \\
\hline BT $\left(\times 10^{-3} \mathrm{~m}^{2} \mathrm{~s}^{-3}\right)$ & 0.67 & 0.64 & 0.49 & 0.39 & 0.24 \\
\hline $\mathrm{ST}\left(\times 10^{-3} \mathrm{~m}^{2} \mathrm{~s}^{-3}\right)$ & 1.02 & 0.66 & 0.37 & 0.26 & 0.23 \\
\hline
\end{tabular}

WS: wind speed; RH: relative humidity; $Q^{*}$ : net radiation; $Q_{\mathrm{H}}$ : sensible heat; $Q_{\mathrm{E}}$ : latent heat; $u_{*}$ : friction velocity; $\bar{e}$ : TKE per unit mass; BT: buoyancy term in TKE; ST: shear term in TKE.

scribed in Sect. 2.1.2, 260 and 540 effective observations were obtained for the convective and stable states, respectively. The MLH data acquired by meteorological radiosondes and by ceilometer were compared for the two types of weather conditions (Fig. 2). Using the MLH calculated by the radiosondes as a reference, the comparison showed that the MLH observed from the ceilometer was overestimated or underestimated in a portion of the samples.

Because the ceilometer determines the MLH by measuring the attenuated backscatter profile, if the concentration of atmospheric particles is relatively low, it will be difficult to determine the MLH based on a sudden change in the backscatter profile, and use of this method will lead to a higher absolute error $\left(\mathrm{MLH}_{\text {ceilometer }}-\mathrm{MLH}_{\text {radiosonde }}\right)$ of the measured MLH (Eresmaa et al., 2006; Muňoz and Undurraga, 2010). When taking the visibility into account, we found that the underestimations of the observed MLH always occurred when visibility was good. However, there were still a number of samples that had low absolute error under conditions of good visibility (Fig. 2). Consequently, clear days with good visibility are not the main reason for underestimation of the observed MLH.

To investigate why the ceilometer results produced underestimations, we analysed those samples with good visibility and small absolute error. The results showed that although the visibility was good, the absolute error of the MLH was still small when the aerosol concentration showed large differences in the vertical direction. After taking the RH and wind vectors into account, we found that underestimations were always accompanied by low RH and strong northerly wind (Figs. 3 and 4). The local meteorological conditions in Beijing indicated that this kind of meteorological condition is usually caused by the bypass of a cold air mass. When strong northerly winds with dry and clear air masses prevail in Beijing, atmospheric aerosols spread rapidly to the downstream region, resulting in a dramatic decrease in local aerosol concentration and good visibility. In addition, the dry air mass suppresses the liquid-phase and heterogeneous reactions of the gaseous precursors and the hygroscopic growth of aerosols can also be neglected. Therefore, the formation of aerosols cannot compensate for the transportation loss, leading to low and uniform aerosol concentrations in the vertical direction. Once the aerosol concentration becomes uniform in the vertical direction, the ceilometer cannot calculate the MLH correctly through sudden changes in the attenuated backscatter profiles, resulting in serious underestimations. An analysis of the relationship between the $R_{\mathrm{B}}$ and the absolute error showed that when the ceilometer-measured MLH is subject to large absolute error, the $R_{\mathrm{B}}$ below $100 \mathrm{~m}$ is approximately 0 (Fig. S1 in the Supplement). Thus, the near-neutral atmospheric stratification caused by the passage of a cold air mass is the primary reason for the serious underestimations.

With respect to overestimations of the ceilometer results, we may take the meteorological radiosonde at 14:00 LT on 29 December 2009 as an example (Fig. 5). The MLH is determined at approximately $1100 \mathrm{~m}$, where the $\theta_{\mathrm{v}}$ and the WS begin to increase; the ozone concentration is transported from the background area, where ozone is present at approximately $40 \mathrm{ppbv}$. However, the ceilometer recorded a higher MLH at approximately $1500 \mathrm{~m}$, where there was a sudden change in the backscatter gradient. When we measured the $\mathrm{PM}_{2.5} / \mathrm{PM}_{10}$ ratio at this moment, we found that the ratio was only 0.15 , a clear characteristic of a sand-dust crossing. Due to the large number of dust particles, the aerosol concentrations became uniform below $1500 \mathrm{~m}$. This led to a sudden change in the backscatter gradient at $1500 \mathrm{~m}$ and made it difficult to identify the real MLH at $1100 \mathrm{~m}$; thus, an erroneously high MLH was determined. This result shows that sand-dust crossing is the main reason for the overestimations (Figs. 2 and 5).

Because the detected aerosol layers are not only the result of ongoing vertical mixing but also always originate from advective transport or past accumulation processes, interpreting 

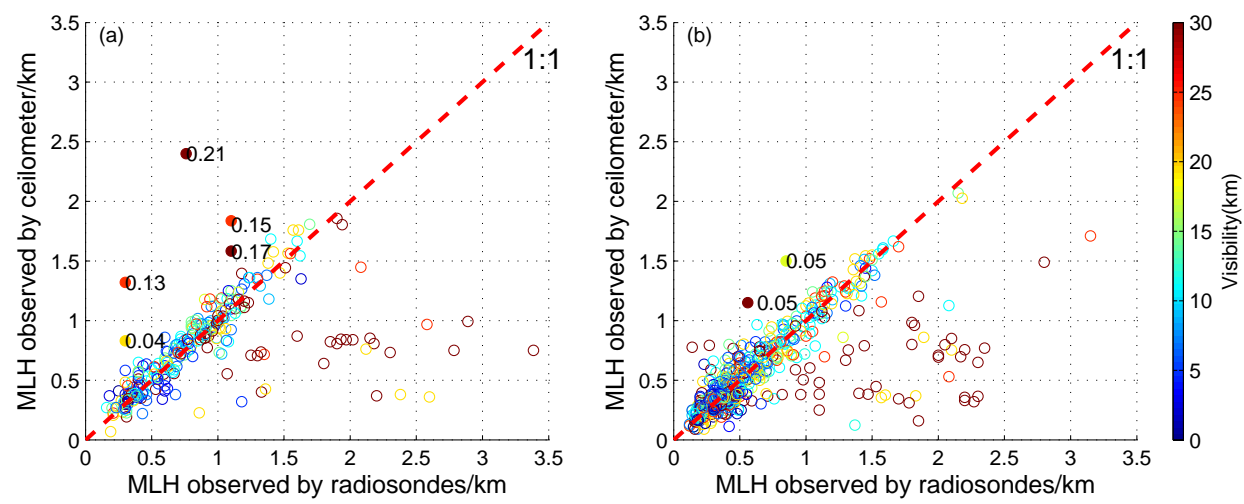

Figure 2. Comparison of MLH between radiosondes and the ceilometer according to visibility for convective (a) and stable (b) states, the number marked with the solid circle refers to the ratios of $\mathrm{PM}_{2.5}$ to $\mathrm{PM}_{10}$ when sand-dust is crossing.
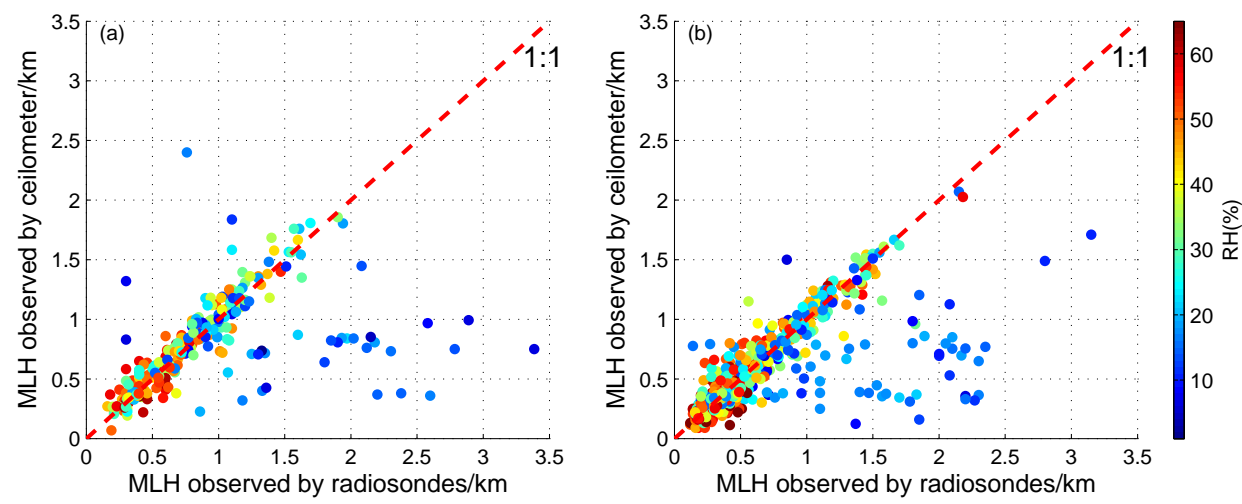

Figure 3. Comparison of MLH between radiosondes and the ceilometer according to RH for convective (a) and stable (b) states.

data from aerosol lidars is often not straightforward (Russell et al., 1974; Coulter, 1979; Baxter, 1991; Batchvarova et al., 1999). Therefore, improving the algorithm cannot resolve the underestimations and overestimations of the ceilometer observations; the only option that can be used to rectify the MLH is to eliminate the data with large absolute error. After determining the reasons for the underestimations and overestimations, the elimination is much easier to implement. For underestimations, the meteorological data were used to eliminate the periods when cold air passed with a sudden change in temperature and WS. For overestimations, we referred to the sand-dust weather almanac to identify the sand-dust days firstly (CMA, 2012, 2013, 2014, 2015). Using the principal described in Sect. 2.1.1, the exact times of sand-dust starting and ending were determined as the times which the ratio of $\mathrm{PM}_{2.5}$ to $\mathrm{PM}_{10}$ suddenly decreased or increased, respectively. Finally, the data obtained during the sand-dust periods were eliminated.

After the screening process, the post-elimination ceilometer data and meteorological radiosondes are strongly correlated, with a correlation coefficient greater than 0.9 , demonstrating the effectiveness of the elimination method (Fig. 6). Consequently, the elimination results are good. This method replaces the time-consuming method of filtering the data manually and is of great practical value for future measurements of MLH with ceilometers.

\subsection{MLH variations}

To provide a detailed description of variations in the MLH, we selected continuous measured MLH and meteorological data over a 3-year period (from December 2009 to November 2012). First, the availability was verified after the MLH elimination by the aforementioned method. The results of the evaluation indicate that the availability in different seasons is significantly negatively correlated with WS and positively correlated with RH (Fig. 7a). For spring and winter seasons with large WS and low RH, the availability is low, whereas for summer and autumn seasons with small WS and high RH, the availability is high. In particular, the availability is lowest in January at $63.5 \%$ and highest in June at $95.0 \%$. The successful retrieval of MLH over the 3-year period is approximately $80 \%$, much higher than in a previous study (Muňoz and Undurraga, 2010).

Using the validated data, we analysed seasonal variations over 3 years. The results showed that the changes of the monthly mean were similar in different years, and no inter- 

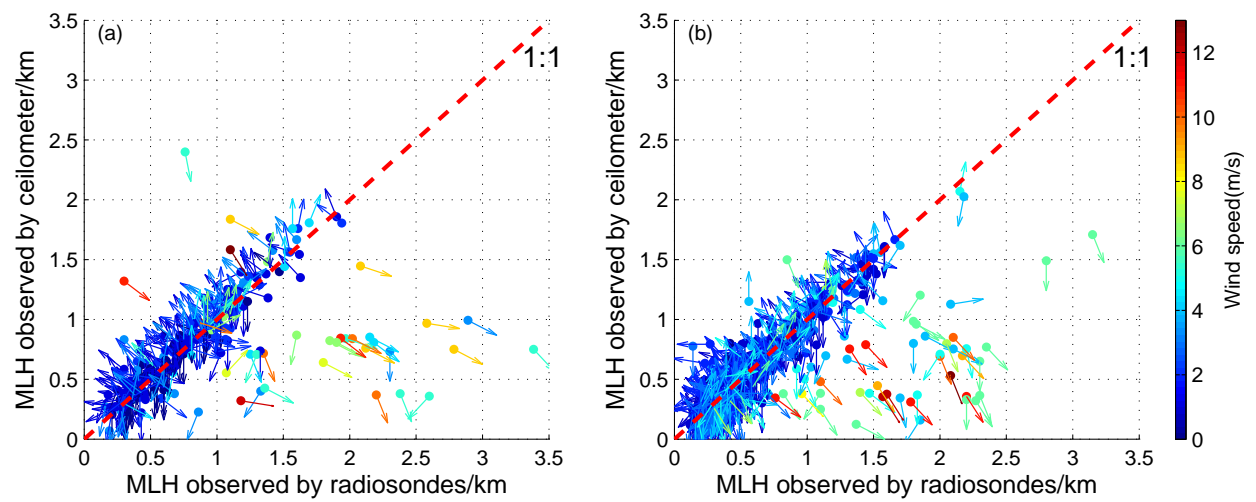

Figure 4. Comparison of MLH between radiosondes and the ceilometer according to wind vectors for convective (a) and stable (b) states.
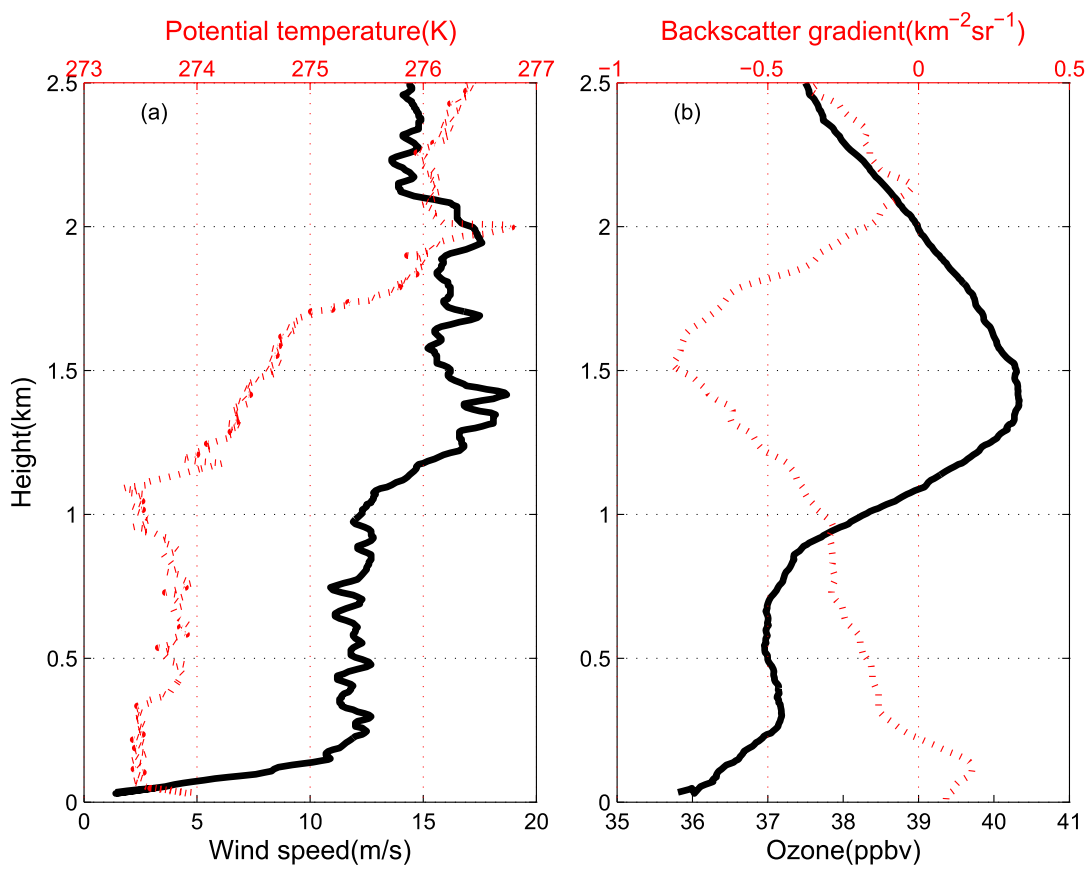

Figure 5. Virtual potential temperature and wind speed (a), and ozone and backscatter gradients (b) at 14:00 LT on 29 December 2009 in Beijing.

annual trend can be found (Fig. 8). Therefore, we examined the averaged seasonal variation, and the monthly mean of the daily minimum, average, and maximum were calculated, respectively. The daily minimum of the mixing layer was high in winter and spring, and low in summer and autumn. The maximum monthly mean of the daily minimum MLH was $351 \pm 185 \mathrm{~m}$ in May, and the minimum was $238 \pm 202 \mathrm{~m}$ in October. The daily minimum MLH generally occurred during night-time under conditions of stable stratification, and the nocturnal stable boundary layer height was closely related to WS (Zilitinkevich and Baklanov, 2002; Hyun et al., 2005); therefore, the seasonal variation in daily minimum MLH was related to the seasonal variation in WS (Fig. 7a).
Compared with the daily minimum MLH, both the monthly mean of the daily average and the maximum MLH exhibited different seasonal variations. As shown in Fig. 7b, two platform periods (from March to August and from October to January) and two transitional periods (February and September) occur for the monthly average MLH. The MLH is similar from October to January at approximately $500 \mathrm{~m}$, and it is similar from March to August at approximately $700 \mathrm{~m}$. February and September are the two transitional months and have values of approximately $600 \mathrm{~m}$. The month with the highest MLH is May at $739 \pm 137 \mathrm{~m}$ (mean \pm standard deviation of the mean), and the MLH is lowest in December at $435 \pm 148 \mathrm{~m}$. The seasonal variation in the daily maximum MLH is similar to the monthly mean 

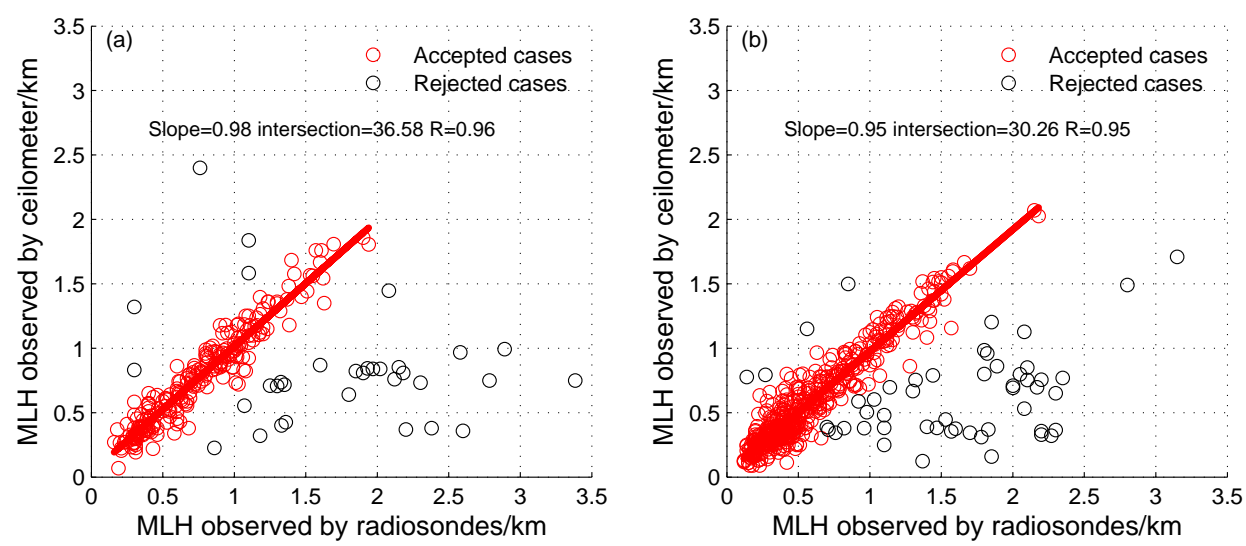

Figure 6. Comparison of MLH between the ceilometer and radiosondes for convective (a) and stable (b) states.
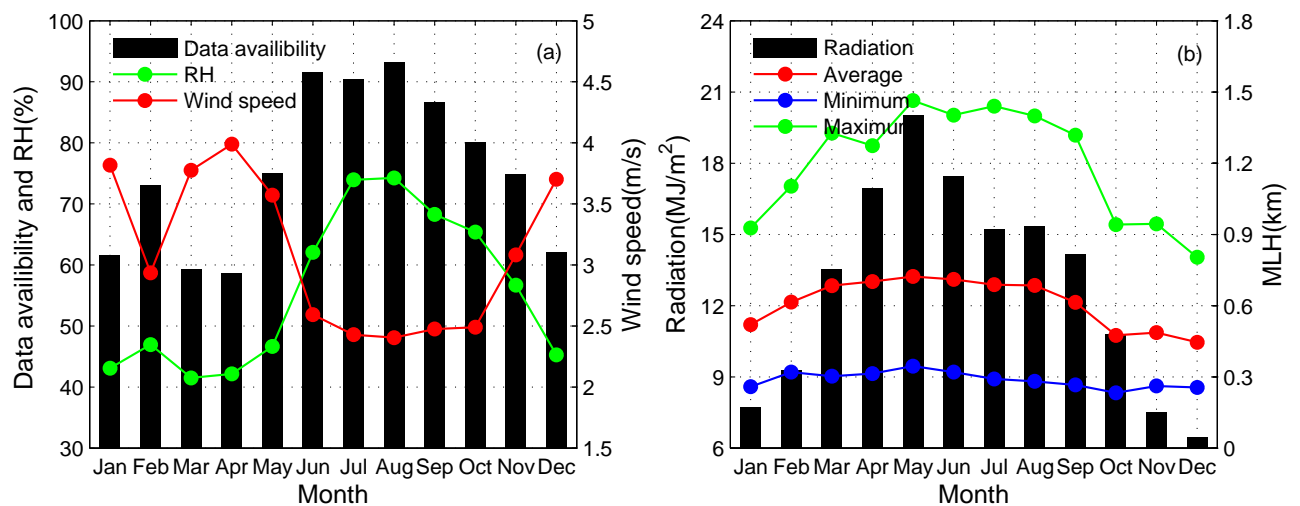

Figure 7. Monthly variations in the effective rate, wind speed, and RH (a), and MLH and total radiation flux (b) in Beijing.

with the highest in May at $1480 \pm 448 \mathrm{~m}$ and the lowest in December at $787 \pm 297 \mathrm{~m}$.

Previous studies have suggested that the seasonal variation in the MLH may be related to radiation flux (Kamp and McKendry, 2010; Muňoz and Undurraga, 2010), but our study was not entirely consistent as shown in Fig. 7b. Although spring had a significantly higher total radiation flux than summer, the MLH in spring is equal to that in summer. This is because more data were eliminated for winter and spring, especially for weather with dry wind and relatively high MLHs. Thus, using the monthly mean of MLH is not a good method by which to analyse the reasons for MLH variations.

To gain a better understanding of the MLH variations, we use the daily mean instead of the monthly mean to do the analysis. As the most simple framework in which we can analyse the MLH variations in Beijing, we consider the thermodynamic model of the mixing layer growth (Stull, 1988), as follows:

$\frac{\partial z_{i}}{\partial t}=\frac{\overline{w^{\prime} \theta_{\mathrm{s}}^{\prime}-w^{\prime} \theta_{z_{i}}^{\prime}}}{\gamma z_{i}}$, where $z_{i}$ is the MLH (m), $t$ is the time (s), $\theta_{\mathrm{s}}$ is the virtual potential temperature near the ground $(\mathrm{K}), \theta_{z_{i}}$ is the virtual potential temperature in the top of the mixing layer $(\mathrm{K})$, and $\gamma$ is the lapse rate of the virtual potential temperature $\left(\mathrm{Km}^{-1}\right)$. Suppose the heat from the ground is the only way to warm the mixing layer and the heat flux at height $z_{i}$ is zero, then the MLH is related to $\overline{w^{\prime} \theta_{\mathrm{s}}^{\prime}}$. Considering that $Q_{\mathrm{H}}$ is defined as the Eq. (1), MLH is correspondingly related to $Q_{\mathrm{H}}$. Therefore, the relationship between daily changes in the $Q_{\mathrm{H}}$ at $280 \mathrm{~m}$ and MLH was analysed. The results showed that the average $Q_{\mathrm{H}}$ and MLH from 12:00 to 17:00 LT were well correlated, with a correlation coefficient of 0.65 . Because net radiation ( $Q^{*}$ ) should be balanced by the $Q_{\mathrm{H}}, Q_{\mathrm{E}}$, and soil heat flux $\left(Q_{\mathrm{G}}\right)$ given as follows (Stull, 1988):

$Q^{*}=Q_{\mathrm{H}}+Q_{\mathrm{E}}+Q_{\mathrm{G}}$,

the strong correlation between the $Q_{\mathrm{H}}$ and MLH proves the dominant role of radiation in the variation of MLH (Fig. 9).

\subsection{Impact of mountainous plain winds on MLH}

We analysed the diurnal variations of MLH on a monthly basis and found that the MLH develops in four stages: from 


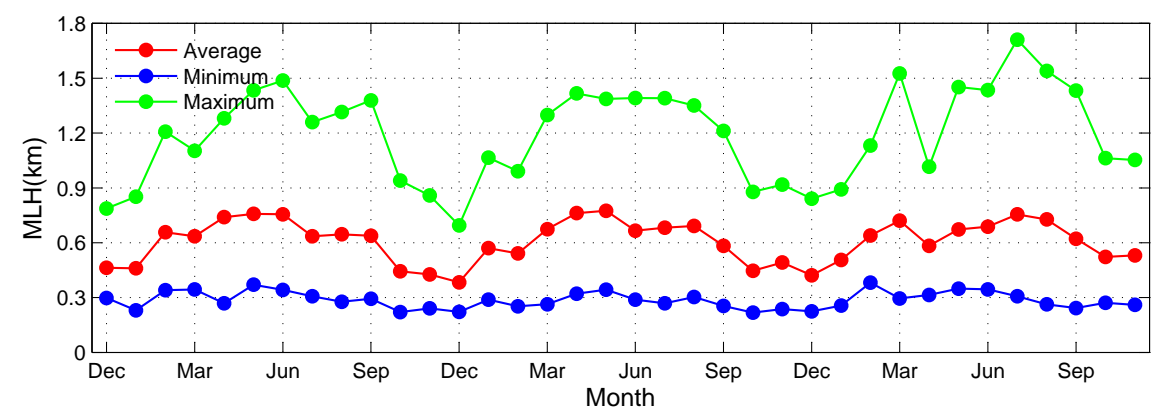

Figure 8. Monthly variations of the MLH from December 2009 to November 2012 in Beijing.

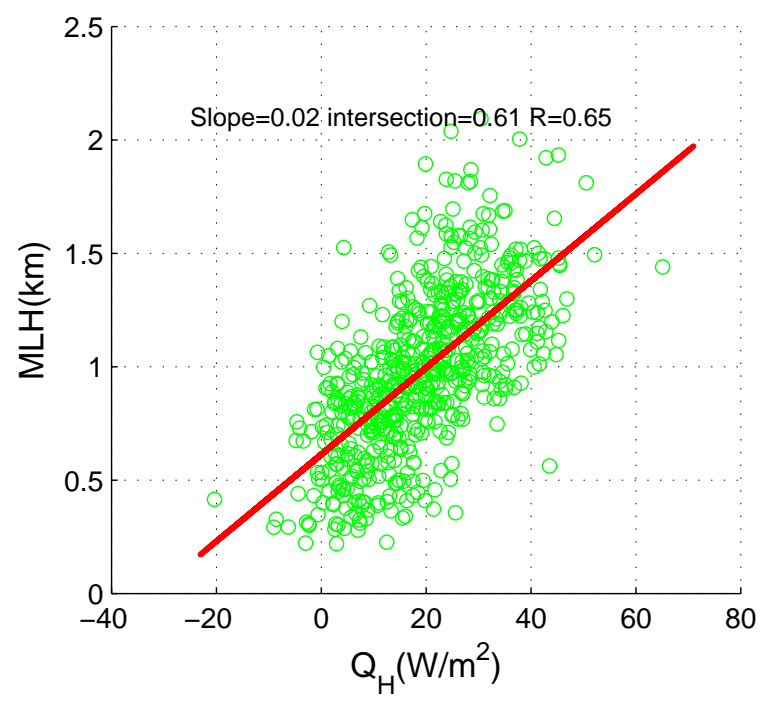

Figure 9. Correlation between the sensible heat $\left(Q_{\mathrm{H}}\right)$ and MLH in Beijing.

09:00 to 14:00 LT, which is the fast development stage; from 14:00 to 18:00 LT, which is the maintenance stage; from 18:00 to 20:00 LT, which is the rapid decrease stage; and from 20:00 LT to the next morning at 08:00 LT, which is the stable boundary layer stage (Fig. S2). These stages of development and dissipation mechanisms are consistent with the description reported by Stull (1988). The daily MLH range is $728,828,562$, and $407 \mathrm{~m}$ for spring, summer, autumn and winter, respectively. The relatively low ranges in autumn and winter are obviously related to the low radiation flux. However, it should be noted that summer has lower radiation and a larger daily range than spring (Fig. 7). Therefore, our study will emphasize the reasons for the differences in the daily MLH range in summer and spring.

As shown in Sect. 3.2, the monthly average MLH is similar between spring and summer. However, when the daily growth rates in spring and summer were compared using the $T$ test, the results showed the difference was significant $(P<0.05)$ between the two seasons. As shown in Fig. 10a, at night-time in spring, the MLH is high and almost constant, whereas at night-time in summer, the MLH shows a gradual decreasing trend. After sunrise and before 12:00 LT, the rate of increase in the MLH is relatively high in spring, reaching $114 \mathrm{~m} \mathrm{~h}^{-1}$, whereas the rate in summer is relatively low, $102 \mathrm{mh}^{-1}$. Between 12:00 and 14:00 LT in spring, the rate of increase in the MLH is $119 \mathrm{mh}^{-1}$, whereas in summer the rate of increase is significantly enhanced, reaching $165 \mathrm{~m} \mathrm{~h}^{-1}$. Such changes reflect the convex and concave characteristics in spring and summer during the development stage of the MLH, respectively.

The development of MLH is mainly related to the turbulent energy and the production of the turbulent energy is closely related to two components: the heat flux caused by radiation $\left(\frac{g}{\overline{\theta_{\mathrm{v}}}} \overline{w^{\prime} \theta_{\mathrm{v}}^{\prime}}\right)$ and the momentum flux generated by wind shear $\left(-\overline{u^{\prime} w^{\prime}} \frac{\partial \bar{u}}{\partial z}\right)$ (Stull, 1988). Because the seasonal variation in heat flux is difficult to explain the daily MLH range, we analysed the seasonal variations of the horizontal wind vector.

To avoid the impact of near-surface buildings on the wind measurements, we selected the wind vector at $100 \mathrm{~m}$ on the Beijing tower. Figure $10 \mathrm{~b}$ shows that there is obvious seasonal variation of the wind vector. In winter and spring, Beijing is affected by the Siberian High; at these times, a strong prevailing northwest wind with dry air mass always occurs. Therefore, winter season is dominated by a northwesterly wind, whereas spring typically exhibits a northwest wind in the morning and a southwest wind in the afternoon. In summer, the northward lift and westward intrusion of a subtropical high causes the southerly moist air mass with small WS to arrive and dominate. Because Beijing is located west of the Taihang Mountains and south of the Yanshan Mountains (Fig. 1), without the passage of large- or medium-scale meteorological systems in the summer, the local mountainous plain wind is superimposed on the southerly air flow and these two systems jointly affect the meteorological characteristics of the North China Plain. Therefore, the alternation between the mountainous winds that begin at 03:00 LT at night and the plain winds that begin at 12:00 LT in the afternoon occurs in summer. In September, with the southward and eastward movement of the subtropical high, the circula- 

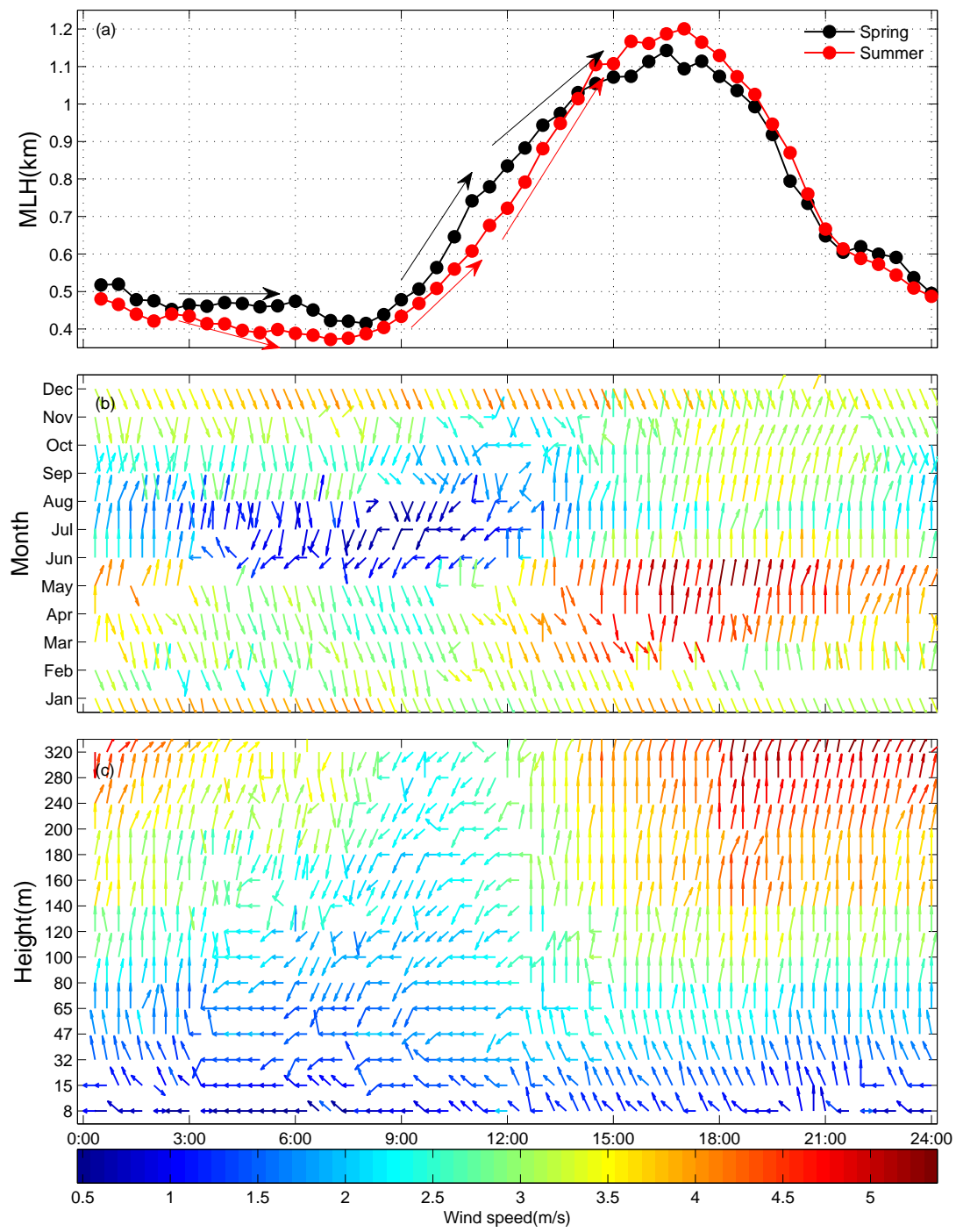

Figure 10. Daily variations in MLH in spring and summer (a), seasonal wind vectors at $100 \mathrm{~m}$ (b), and vertical profiles of wind vectors in July (c) in Beijing.

tion of mountainous plain winds starts to weaken, and this circulation disappears in November.

When this regional circulation occurs along with surface cooling that occurs at night in summer, the cold air near the surface forms a shallow down-sliding flow from the northeast to the southwest. The cold air flows into the North China Plain and accumulates in a cold pool, increasing the thickness of the inversion layer, and the thickness of the mixing layer gradually decreases. After sunrise, the radiation increases; the MLH increases rapidly under the impact of thermal buoyancy lift, and this type of cold drainage flow is maintained until 12:00 LT. After 12:00 LT, the plain wind from the southwesterly direction gradually dominates and is maintained until approximately 03:00 LT in the morning of the next day. According to Fig. 10c, from 03:00 to 12:00 LT in summer, the troposphere below $300 \mathrm{~m}$ gradually cools down from low to high due to the cold drainage flow in the northeasterly direction, and the MLH exhibits a gradually decreasing trend from 03:00 to 06:00 LT. However, this trend does not occur in spring (Fig. 10a). Similarly, between 09:00 and 12:00 LT in summer, the cold drainage flow suppresses the development of the MLH with a low growth rate; in spring, without this inhibitory effect, the growth rate of the MLH is high. After 12:00 LT in summer, the southerly plain wind causes the growth rate to increase between 12:00 and 14:00 LT.

In summary, the mountainous wind in summer causes the mixing layer to decline gradually at night; this also suppresses the development of the mixing layer before noon, and the prevalence of plain winds after noon causes the mixing layer to increase rapidly. Therefore, compared to the spring, the regional circulation in summer produces a concave-down 
variation in the rapid development stage of the MLH in summer. Although some interpretations for the influences of mountain plain winds are given, more intensive observations over northern China are suggested in order to analyse this phenomenon by meteorological radiosondes and additional observations.

\subsection{Implications for air pollution}

\subsubsection{Thermal/dynamic parameters under different degrees of pollution}

To analyse variations in the thermal dynamic parameters inside atmospheric mixing layers under different degrees of pollution, visibility was used as a reference. WS, $\mathrm{RH}, Q_{\mathrm{H}}$, $Q_{\mathrm{E}}, u_{*}$, and $\bar{e}$ at $280 \mathrm{~m}$ were obtained according to visibility (Fig. 11). Clear days were defined as days when the visibility is $\geq 10 \mathrm{~km}$, and slight, light, medium, and heavy hazy days corresponded with $5 \mathrm{~km} \leq$ visibility $<10 \mathrm{~km}$, $3 \mathrm{~km} \leq$ visibility $<5 \mathrm{~km}, 2 \mathrm{~km} \leq$ visibility $<3 \mathrm{~km}$ and visibility $<2 \mathrm{~km}$, respectively (CMA, 2010). The statistics of the thermal/dynamic parameters were obtained under different degrees of air pollution (Table 2). On clear days with atmospheric visibility $\geq 10 \mathrm{~km}$, RH was the lowest, with an average of $43.3 \%$, and $Q_{\mathrm{H}}, u_{*}$ and $\bar{e}$ were the highest, averaging $20.4 \mathrm{~W} \mathrm{~m}^{-2}, 0.45 \mathrm{~m} \mathrm{~s}^{-1}$, and $0.99 \mathrm{~m}^{2} \mathrm{~s}^{-2}$, respectively. The MLH was $664 \mathrm{~m}$ on average, and the maximum in the afternoon reached $1145 \mathrm{~m}$. Compared with clear days, during slight haze pollution the RH significantly increased to $63.1 \%$, and the $u_{*}$ and $\bar{e}$ significantly declined to $0.32 \mathrm{~m} \mathrm{~s}^{-1}$ and $0.64 \mathrm{~m}^{2} \mathrm{~s}^{-2}$, respectively, with a reduction of approximately $30 \%$; the $Q_{\mathrm{H}}$ and MLH was $19.7 \mathrm{~W} \mathrm{~m}^{-2}$ and $671 \mathrm{~m}$, respectively, without any significant changes. With the pollution aggravated, the RH continued to increase; during light, medium, and heavy haze it reached to $73.4,79.6$, and $86.4 \%$, respectively. The $u_{*}$ and $\bar{e}$ remained almost constant, and the $Q_{\mathrm{H}}$ and MLH showed a significantly declining trend. Refer to Table 2 for the measured values under light, medium, and heavy haze.

In summary, when clear days change to slight haze, the WS, $u_{*}$, and $\bar{e}$ decline significantly but the $Q_{\mathrm{H}}$ and MLH do not change significantly. When slight haze evolves to light, medium, and heavy haze, significant changes in $u_{*}$ and $\bar{e}$ do not occur, but the $Q_{\mathrm{H}}$ and MLH decrease significantly. It should be noted that although the RH varied considerably at different pollution stages, significant changes in $Q_{\mathrm{E}}$ did not occur; its values were $18.7,19.9,21.5,18.8$, and $19.8 \mathrm{~W} \mathrm{~m}^{-2}$ on clear days and under conditions of slight, light, medium, and heavy haze, respectively. Thus, when clear days change to slight haze, dynamic effects have a relatively large impact on the mixing layer, whereas when slight haze evolves to heavy haze, thermodynamic effects play a dominant role.

To verify these results, we examined the TKE budget equation. If we presume a horizontal average and neglect the advection of wind, the forecast equation of the TKE can be written as follows (Stull, 1988; Garratt, 1992):

$$
\begin{aligned}
\frac{\partial \bar{e}}{\partial t} & =-\overline{u^{\prime} w^{\prime}} \frac{\partial \bar{u}}{\partial z}+\frac{g}{\overline{\theta_{\mathrm{v}}}} \overline{w^{\prime} \theta_{\mathrm{v}}{ }^{\prime}}-\frac{\partial\left(\overline{w^{\prime} e}\right)}{\partial z} \\
& -\frac{1}{\rho} \frac{\partial\left(\overline{w^{\prime} p^{\prime}}\right)}{\partial z}-\varepsilon,
\end{aligned}
$$

where $p$ is the air pressure $(\mathrm{Pa})$, and $\varepsilon$ is the dissipation term of TKE $\left(\mathrm{m}^{2} \mathrm{~s}^{-3}\right)$. The first term on the right side of the equation is the production and loss term caused by wind shear; the second term is the buoyancy production and depletion term, and the third and fourth terms are the turbulent transport and pressure-related terms, respectively. Because the turbulent transport term does not generate or destroy the TKE but simply moves the TKE from one position to another or redistributes it, the integral of this term in the mixing layer remains constant at zero. Moreover, because the time period of pollution usually corresponds to the stable state, the pressurerelated term is also small at this time. Therefore, we did not consider the third and fourth terms of TKE in this study.

To differentiate the contribution of horizontal and vertical turbulence to the TKE, the shear and buoyancy terms in the TKE forecast equation were analysed as in the previous study (Ye et al., 2015). When visibility decreases from 10 to $5 \mathrm{~km}$, the variation in the buoyancy term is insignificant, but the reduction in the shear term is near $70 \%$; when visibility decreases from 5 to $1 \mathrm{~km}$, the variation in the shear term is insignificant, but the decrease in the buoyancy term is approximately $60 \%$ (Fig. 11d). Therefore, the key meteorological factor for the conversion from clear to slight hazy days is the decrease of the shear term in TKE, and it is mainly characterized by a significant reduction in the horizontal wind velocity; for the conversion from slight haze to light, medium, and heavy haze, the decrease of the buoyancy term in TKE is crucial, and it is mainly characterized by a significant reduction in the $Q_{\mathrm{H}}$ and MLH.

\subsubsection{Critical meteorological factors for air pollution}

At least one previous study indicates when the MLH decreases, the concentration of atmospheric particles increases and visibility decreases (Tang et al., 2015). However, analyses of the MLH and particle concentration or visibility indicates that the correlation of these is not strong ( $\mathrm{Li}$ et al., 2015). We analysed the correlation between daily averages of MLH and visibility in this study and found that the correlation between them is poor, with a correlation coefficient of only 0.08 ; this finding is consistent with the results of a previous study (Li et al., 2015).

According to the discussion in Sect. 3.4.1, in addition to MLH, WS is another factor in controlling air pollution. The MLH and WS represent the vertical and horizontal diffusion capabilities of pollutants, respectively. Synthesizing these two factors, the product of the MLH and the WS (ven- 

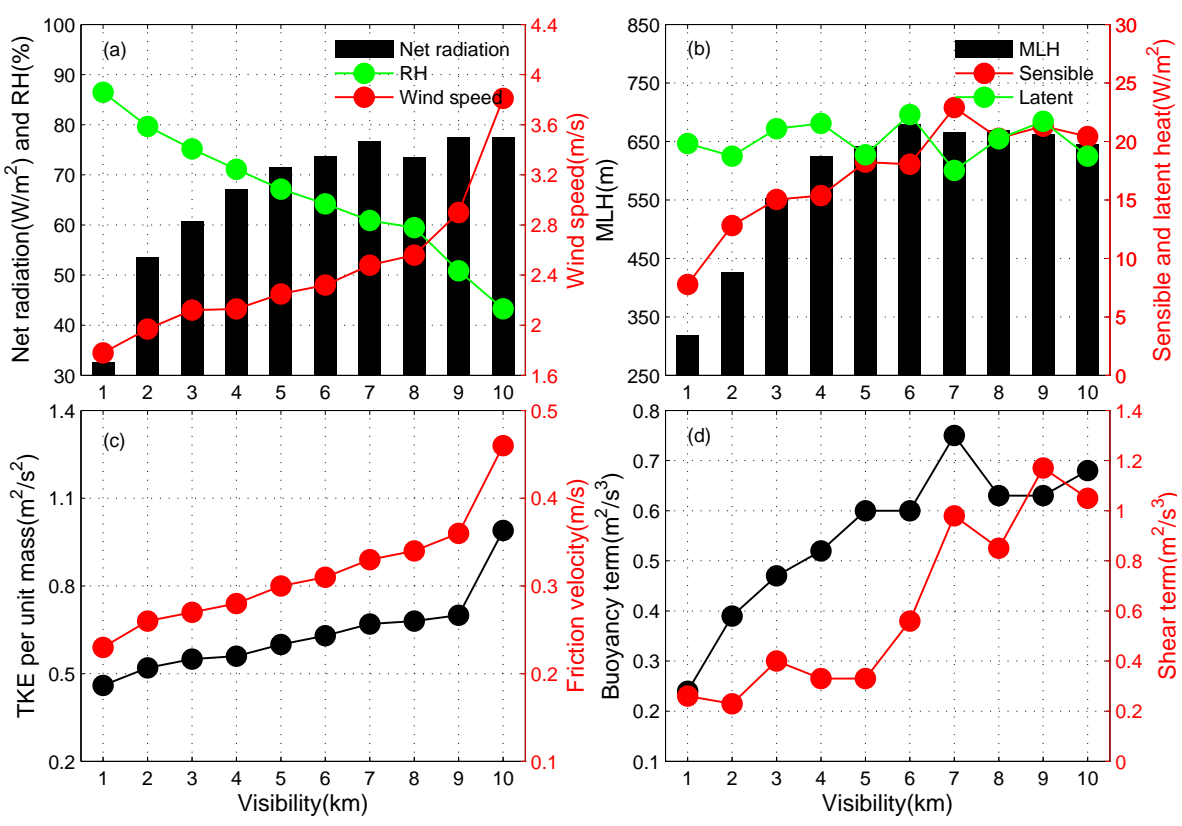

Figure 11. Variations in net radiation, RH, and wind speed (a), MLH, sensible and latent heat (b), TKE per unit mass, and friction velocity (c), and buoyancy and shear term in TKE (d) according to visibility.
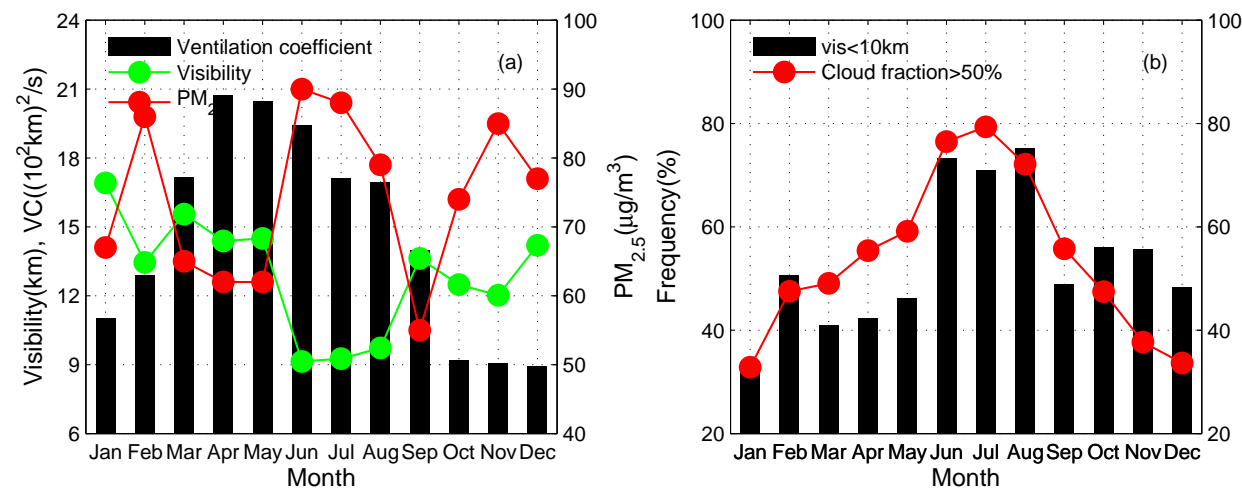

Figure 12. Monthly variations in visibility, $\mathrm{PM}_{2.5}$, and ventilation coefficients (a) and frequency of visibility $<10 \mathrm{~km}$, and cloud fraction $>50 \%$ (b) in Beijing.

tilation coefficient: VC) is usually used as an index to measure the capability of atmospheric diffusion; a higher VC indicates stronger capability (Tang et al., 2015). As shown in Fig. 12a, the VC is highest in spring with approximately $2000 \mathrm{~m}^{2} \mathrm{~s}^{-1}$, followed by summer, autumn, and winter, when the VC is 1782,1095 and $1072 \mathrm{~m}^{2} \mathrm{~s}^{-1}$, respectively. However, although the atmospheric diffusion capability in summer is much better than that in autumn and winter, the visibility is lowest $(\sim 9 \mathrm{~km})$ and the $\mathrm{PM}_{2.5}$ concentration is highest $\left(\sim 85 \mu \mathrm{g} \mathrm{m}^{-3}\right)$ in summer (Fig. 12a). By focusing on visibility $\geq 10 \mathrm{~km}$ and visibility $<10 \mathrm{~km}$ separately, we find that the frequency of haze occurrence is highest (up to $73 \%$ ) in summer, whereas it is approximately $40 \%$ in other seasons (Fig. 12b). Therefore, strong diffusion capability cannot explain the occurrence of heavy pollution in summer.
To obtain a clear understanding of the relationship between the atmospheric MLH and air pollution, we analysed the correlation between daily averages of the MLH and visibility according to the $\mathrm{RH}$ and found that the relationship between them showed significant differences under different $\mathrm{RH}$. When the RH was lower than $80 \%$, the correlation between the MLH and visibility was poor, but when the RH exceeded $80 \%$, the correlation coefficient of these two measurements significantly increased to as much as 0.72 (Table 3 and Fig. 13). If we assume that no transport from other regions occurs, local contributions (local emissions and secondary formation) will dominate the particle concentration; if we further suppose that the local emission is constant every day, due to the dominant role of the aqueous, heterogeneous, and hydroscopic processes for the formation of par- 
Table 3. Correlation coefficients $(R)$ between the MLH and visibility according to RH (\%).

\begin{tabular}{llllllll}
\hline & $\mathrm{RH} \leq 40$ & $40<\mathrm{RH} \leq 50$ & $50<\mathrm{RH} \leq 60$ & $60<\mathrm{RH} \leq 70$ & $70<\mathrm{RH} \leq 80$ & $80<\mathrm{RH} \leq 90$ & $\mathrm{RH}>90$ \\
\hline$R$ & 0.15 & 0.04 & 0.01 & 0.09 & 0.41 & 0.70 & 0.77 \\
\hline
\end{tabular}

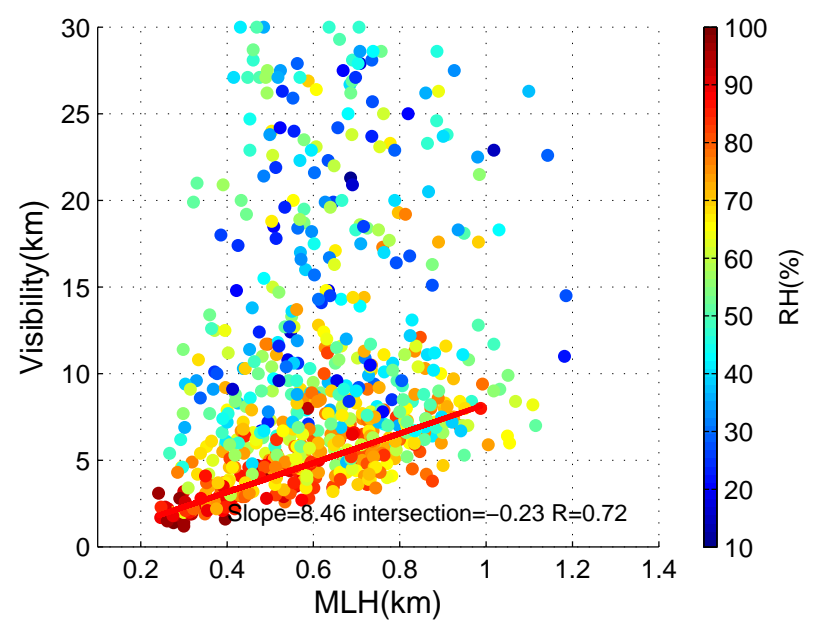

Figure 13. Correlation between the MLH and visibility according to RH in Beijing.

ticles in Beijing (Guo et al., 2014; Sun et al., 2013), there will be little difference in the formation of particles under a fixed RH, and the column concentration in the MLH will be almost constant. Under such circumstances, the relationship between the MLH and visibility should be strong. Thus, poor correlation between the MLH and visibility indicates a significant influence from regional transportation, and their good correlation indicates the dominant role of local contributions. Tang et al. (2015) found that in light pollution, regional transport contributes heavily, whereas in heavy pollution, local contributions dominate. Because low and high $\mathrm{RH}$ correspond to light and heavy pollution, respectively, the two conclusions are strongly consistent.

To clarify the contributions of local emissions and secondary formation during high RH conditions, we analysed the chemical compositions in $\mathrm{PM}_{1}$ under different degrees of air pollution (Fig. 14). As the air pollution aggravated, the mass percentage of $\mathrm{SO}_{4}^{2+}, \mathrm{NO}_{3}^{-}$, and $\mathrm{NH}_{4}^{+}$with strong hygroscopicity increases from 31.8 to $61.9 \%$ from clear to heavy hazy days, whereas the mass percentage of OM with weak hygroscopicity decreases from 58.0 to $33.7 \%$ during the transition of air pollution. Thus, the aerosols exhibit higher sulphate, nitrate, and ammonium ratios on hazy days, which indicates the dominant role of the secondary formation.

From the aforementioned analyses, the reasons for the relationships observed under conditions of low and high RH can be clearly understood. Under low RH condition, since the significant impact of the regional transportation,

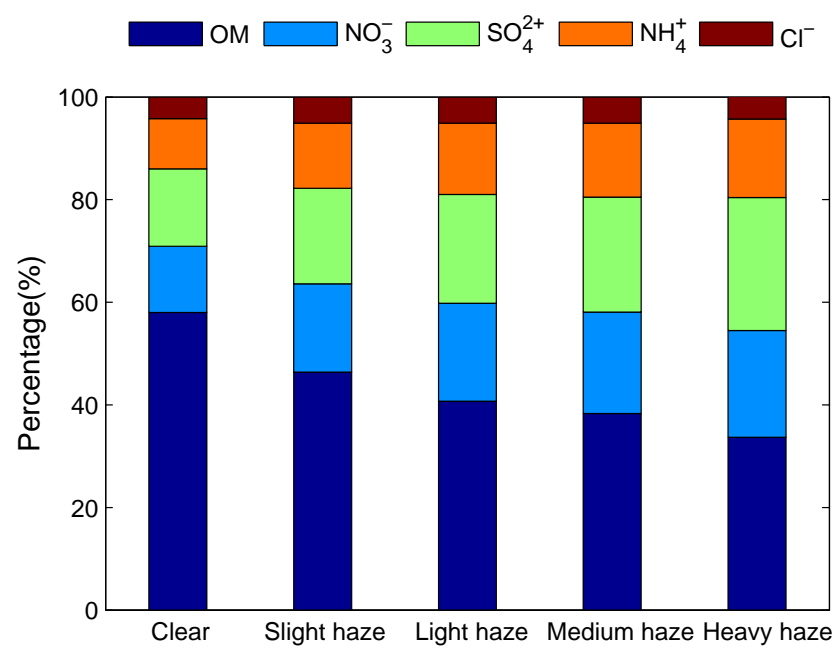

Figure 14. Mass percentage of $\mathrm{OM}, \mathrm{NO}_{3}^{-}, \mathrm{SO}_{4}^{2+}, \mathrm{NH}_{4}^{+}$and $\mathrm{Cl}^{-}$in $\mathrm{PM}_{1}$ under different degrees of air pollution in Beijing.

the processes of local emissions, regional transportation, and physicochemical formation jointly dominate the concentration of atmospheric particles; thus, the poor correlation between the MLH and visibility occurs due to the multi-source of particles. For high RH, the RH plays an important role in transforming the trace gases to aerosols. Thus, an increase in the RH is favourable for the formation of particles from the liquid-phase, heterogeneous reactions and the hygroscopic growth processes, and the primary source of particles will change to local humidity-related physicochemical processes during heavy pollution periods. The strong correlation of these factors under high $\mathrm{RH}$ indicates the dominant role of local secondary processes in heavy pollution.

Overall, the high correlation between the MLH and visibility under high RH indicates that humidity-related physicochemical processes is the primary source of atmospheric particles in heavy pollution and that the dissipation of atmospheric particles mainly depends on the vertical diffusion capability, which is dominated by the atmospheric MLH. From the aforementioned conclusion, the MLH and RH are extracted as the key meteorological factors for the evolution of heavy air pollution, a finding that is relevant to the dissipation and formation of the atmospheric particles.

After determining the critical meteorological factors for air pollution, the cause of the poor visibility in summer can be analysed according to the aforementioned conclusions. As shown in Fig. 7a, summer exhibits higher RH and lower WS. The meteorological conditions in summer shows that 
low WS is a prerequisite for hazy days and that high RH is conducive to the formation of particles. In addition, due to the intrusion of the west Pacific subtropical high, summer is occupied by more than $70 \%$ by the highest frequency of cloud fraction $>50 \%$ (Fig. 12b). When this cloud fraction increases, radiation levels will dramatically decline, and the MLH will decrease significantly as well. Such conditions cause a rapid weakening of the atmospheric diffusion capability along with a more rapid formation of particles under high RH; heavy pollution will occur frequently, thus leading to the enhanced concentration of particles and decreased visibility (Fig. 12a).

\section{Conclusions}

Continuous high-resolution observations of MLH are required to understand the characteristics of the atmospheric mixing layer in the Beijing and North China Plain areas. To acquire the high-resolution observations of MLH, a study using a ceilometer was performed from July 2009 to December 2012 in the Beijing urban area.

Based on a comparison with radiosondes, we determined that the ceilometer underestimates the MLH during nearneutral stratification caused by strong winds and that it overestimates the MLH during dust crossing. By combining meteorological, $\mathrm{PM}_{2.5}$, and $\mathrm{PM}_{10}$ data, we screened the observation results for the MLH; the availability of the acquired data is close to $80 \%$. The screened ceilometer observations are fairly consistent with the meteorological radiosondes, with a correlation coefficient greater than 0.9. This method replaces the time-consuming method of filtering the data manually and is of great practical value for future measurements of the MLH with ceilometers.

The characteristics of the MLH indicate that the MLH in Beijing is low in autumn and winter, and high in spring and summer. There is a significant correlation between the $Q_{\mathrm{H}}$ and MLH, which characterizes the dominant role of the radiation in the variation of the MLH. In addition, the diurnal cycle in the MLH during summer is also affected by the circulation of mountainous plain winds. The mountainous wind in summer causes a gradual decline in the mixing layer at night, which suppresses its development before noon, and the plain wind after noon contributes to the increase in the MLH. Therefore, compared with spring, the mountainous plain winds in summer lead to a concave-down of the mixing layer in the fast development stage.

By applying visibility as an index for the classification of degree of air pollution, it is found that in comparison with clear days, changes in the $Q_{\mathrm{H}}$ and buoyancy term in TKE are insignificant on slight hazy days, but a reduction in the shear term is obvious; in comparison with slight hazy days, the variation of the shear term in TKE is insignificant, but the declines in $Q_{\mathrm{H}}$ and the buoyancy term in TKE are significant. At the slight pollution stage, the air pollution has nothing to do with the MLH but depends on the horizontal diffusion capability as affected by the horizontal wind speed. At the heavy pollution stage, the air pollution is determined by the vertical diffusion capability as affected by the MLH.

Although the correlation between the daily MLH and visibility is very poor, the correlation between them is significantly enhanced when the RH increases. The high correlation between the MLH and visibility under high RH indicates that humidity-related physicochemical processes is the primary source of atmospheric particles under heavy pollution, whereas the dissipation of atmospheric particles depends primarily on the vertical diffusion capability, which is dominated by the atmospheric MLH.

The aforementioned results provide reliable basic data for better portraying the structure of the boundary layer and improving the parameterizations of the boundary layer in meteorological models. Studies of the atmospheric mixing layer and its thermal dynamic parameters at different stages of air pollution reveal the critical meteorological factors for the formation, evolution, and dissipation of heavy pollution, thus providing useful empirical information for improving atmospheric chemistry models and the forecasting and warning of air pollution.

\section{The Supplement related to this article is available online at doi:10.5194/acp-16-2459-2016-supplement.}

Acknowledgements. This work was supported by CAS Strategic Priority Research Program Grants (nos. XDB05020000 and XDA05100100), the National Natural Science Foundation of China (nos. 41230642 and 41222033) and the National Data Sharing Infrastructure of Earth System Science. We also gratefully acknowledge the Department of Atmospheric Science, College of Engineering, University of Wyoming for the provision of the meteorological data used in this publication.

Edited by: C. Hoose

\section{References}

Aron, R.: Mixing height - an inconsistent indicator of potential air pollution concentrations, Atmos. Environ., 17, 2193-2197, 1983.

Batchvarova, E., Cai, X., Gryning, S. E., and Steyn, D.: Modelling internal boundary layer development in a region with complex coastline, Bound.-Lay. Meteorol., 90, 1-20, 1999.

Baxter, R. A.: Determination of mixing heights from data collected during the 1985 SCCCAMP field program, J. Appl. Meteorol., 30, 598-606, 1991.

Beyrich, F.: Mixing height estimation from SODAR data - a critical discussion, Atmos. Environ., 31, 3941-3953, 1997.

Chen, Y., Zhao, C., Zhang, Q., Deng, Z., Huang, M., and Ma, X.: Aircraft study of Mountain Chimney Effect of Beijing, China, J. Geophys. Res., 114, D08306, doi:10.1029/2008JD010610, 2009. 
Chen, W., Kuze, H., Uchiyama, A., Suzuki, Y., and Takeuchi, N.: One-year observation of urban mixed layer characteristics at Tsukuba, Japan using a micro pulse lidar, Atmos. Environ., 35, 4273-4280, doi:10.1016/S1352-2310(01)00181-9, 2001.

Chen, Z., Liu, W., Zhang, Y., He, J., and Ruan, J.: Mixing layer height and meteorological measurements in Hefei China during the total solar eclipse of 22 July, 2009, Opt. Laser Technol., 43, 50-54, doi:10.1016/j.optlastec.2010.04.022, 2011.

CMA (China Meteorological Administration): Observation and forecasting levels of haze, QX/T 113-2010, Beijing, 2010.

CMA (China Meteorological Administration): sand-dust weather almanac (2009), China Meteorological Press, Beijing, 2012.

CMA (China Meteorological Administration): sand-dust weather almanac (2010), China Meteorological Press, Beijing, 2013.

CMA (China Meteorological Administration): sand-dust weather almanac (2011), China Meteorological Press, Beijing, 2014.

CMA (China Meteorological Administration): sand-dust weather almanac (2012), China Meteorological Press, Beijing, 2015.

Coulter, R. L.: A comparison of three methods for measuring mixing layer height, J. Appl. Meteorol., 18, 1495-1499, 1979.

Devara, P. C. S., Ernest, R. P., Murthy, B. S., Pandithurai, G., Sharma, S., and Vernekar, K. G.: Intercomparison of nocturnal lower-atmospheric structure observed with LIDAR and SODAR techniques at Pune, India, J. Appl. Meteorol., 34, 1375-1383, 1995.

Ding, G. A., Chen, Z. Y., Gao, Z. Q., Yao, W. Q., Li, Y., Cheng, X. H., Meng, Z. Y., Yu, H. Q., Wong, K. H., Wang, S. F., and Miao, Q. J.: Vertical structures of $\mathrm{PM}_{10}$ and $\mathrm{PM}_{2.5}$ and their dynamical character in low atmosphere in Beijing urban areas, Sci. China Ser. D, 35, 31-44, 2005.

Emeis, S. and Schäfer, K.: Remote sensing methods to investigate boundary-layer structures relevant to air pollution in cities, Bound.-Lay. Meteorol., 121, 377-385, 2006.

Emeis, S., Münkel, C., Vogt, S., Müller, W. J., and Schäfer, K.: Atmospheric boundary-layer structure from simultaneous SODAR, RASS, and ceilometer measurements, Atmos. Environ., 38, 273 286, 2004

Emeis, S., Jahn, C., Münkel, C., Münsterer, C., and Schäfer, K.: Multiple atmospheric layering and mixing-layer height in the Inn valley observed by remote sensing, Meteorol. Z., 16, 415-424, 2007.

Emeis, S., Schäfer, K., and Münkel, C.: Surface-based remote sensing of the mixing-layer height - a review, Meteorol. Z., 17, 621630, 2008

Emeis, S., Schäfer, K., Münkel, C., Friedl, R., and Suppan, P.: Evaluation of the interpretation of ceilometer data with RASS and radiosonde data, Bound.-Lay. Meteorol., 143, 25-35, 2012.

Eresmaa, N., Karppinen, A., Joffre, S. M., Räsänen, J., and Talvitie, H.: Mixing height determination by ceilometer, Atmos. Chem. Phys., 6, 1485-1493, doi:10.5194/acp-6-1485-2006, 2006.

Flentje, H., Heese, B., Reichardt, J., and Thomas, W.: Aerosol profiling using the ceilometer network of the German Meteorological Service, Atmos. Meas. Tech. Discuss., 3, 3643-3673, doi:10.5194/amtd-3-3643-2010, 2010.

Garratt, J. R.: The Atmospheric Boundary Layer, Cambridge University Press, Cambridge, UK, 1992.

Guo, S., Hu, M.,Zamora, M., Peng, J., Shang, D., Zheng, J., Du, Z., Wu, Z., Shao, M., Zeng, L., Molina, M., and Zhang, R.: Eluci- dating severe urban haze formation in China, P. Natl. Acad. Sci. USA, 111, 17373-17378, doi:10.1073/pnas.1419604111, 2014.

Haeffelin, M., Angelini, F., Morille, Y., Martucci, G., Frey, S., Gobbi, G. P., Lolli, S., O'Dowd, C. D., Sauvage, L., XuerefRémy, I., Wastine, B., and Feist, D. G: Evaluation of mixingheight retrievals from automatic profiling lidars and ceilometers in view of future integrated networks in Europe, Bound.-Lay. Meteorol., 143, 49-75, 2012.

Hägeli, P., Steyn, D. G., and Strawbridge, K. B.: Spatial and temporal variability of mixed-layer depth and entrainment zone thickness, Bound.-Lay. Meteorol., 97, 47-71, 2000.

He, Q. and Mao, J.: Observation of urban mixed layer at Beijing using a micro pulse lidar, Acta Meteorol. Sin., 63, 374-384, 2005 (in Chinese).

He, Q. S., Mao, J. T., Chen, J. Y., and Hu, Y. Y.: Observational and modeling studies of urban atmospheric boundary-layer height and its evolution mechanisms, Atmos. Environ., 40, 1064-1077, doi:10.1016/j.atmosenv.2005.11.016, 2006.

Hennemuth, B. and Lammert, A.: Determination of the atmospheric boundary layer height from radiosonde and lidar backscatter, Bound.-Lay. Meteorol., 120, 181-200, 2006.

Holzworth, C. G.: Estimates of mean maximum mixing depths in the contiguous United States, Mon. Weather Rev., 92, 235-242, 1964.

Holzworth, C. G.: Mixing depths, wind speeds and air pollution potential for selected locations in the United States, J. Appl. Meteorol., 6, 1039-1044, 1967.

Hu, B., Wang, Y. S., and Liu, G. R.: Relationship between net radiation and broadband solar radiation in the Tibetan Plateau, Adv. Atmos. Sci., 29, 135-143, doi:10.1007/s00376-011-02216, 2012.

Hu, X., Ma, Z., Lin, W., Zhang, H., Hu, J., Wang, Y., Xu, X., Fuentes, J. D., and Xue, M.: Impact of the Loess Plateau on the atmospheric boundary layer structure and air quality in the North China Plain: a case study, Sci. Total Environ., 499, 228237, doi:10.1016/j.scitotenv.2014.08.053, 2014.

Hyun, Y., Kim, K., and Ha, K.: A comparison of methods to estimate the height of stable boundary layer over a temperate grassland, Agr. Forest Meteorol., 132, 132-142, doi:10.1016/j.agrformet.2005.03.010, 2005.

Kamp, D. and McKendry, I.: Diurnal and seasonal trends in convective mixed-layer heights estimated from two years of continuous ceilometer observations in Vancouver, BC, Bound.-Lay. Meteorol., 137, 459-475, 2010.

Kunz, G. J., Leeuw, G., Becker, E., and O'Dowd, C. D.: Lidar observations of atmospheric boundary layer structure and sea spray aerosol plumes generation and transport at Mace Head, Ireland (PARFORCE experiment), J. Geophys. Res., 107, 8106, doi:10.1029/2001JD001240, 2002.

Li, M., Tang, G., Huang, J., Liu, Z., An, J., and Wang, Y.: Characteristics of winter atmospheric mixing layer height in BeijingTianjin-Hebei region and their relationship with the atmospheric pollution, Environ. Sci., 36, 1935-1943, 2015 (in Chinese).

Liu, Z., Hu, B., Wang, L., Wu, F., Gao, W., and Wang, Y.: Seasonal and diurnal variation in particulate matter $\left(\mathrm{PM}_{10}\right.$ and $\left.\mathrm{PM}_{2.5}\right)$ at an urban site of Beijing: analyses from a 9-year study, Environ. Sci. Pollut. R., 22, 627-642, 2014. 
Luo, T., Yuan, R., and Wang, Z.: Lidar-based remote sensing of atmospheric boundary layer height over land and ocean, Atmos. Meas. Tech., 7, 173-182, doi:10.5194/amt-7-173-2014, 2014.

McKendry, I. G., Kamp, D., Strawbridge, K. B., Christen, A., and Crawford, B.: Simultaneous observations of boundary-layer aerosol layers with CL31 ceilometer and $1064 / 532 \mathrm{~nm}$ lidar, Atmos. Environ., 43, 5847-5852, doi:10.1016/j.atmosenv.2009.07.063, 2009.

Münkel, C. and Räsänen, J.: New optical concept for commercial lidar ceilometers scanning the boundary layer, P. SPIE, 5571, 364374, 2004

Münkel, C., Eresmaa, N., Räsänen, J., and Karppinene, A.: Retrieval of mixing height and dust concentration with lidar ceilometer, Bound.-Lay. Meteorol., 124, 117-128, 2007.

Muňoz, R. C. and Undurraga, A. A.: Daytime mixed layer over the Santiago Basin: Description of two years of observations with a lidar ceilometer, J. Appl. Meteorol. Clim., 49, 1728-1741, 2010.

Pappalardo, G., Amodeo, A., Apituley, A., Comeron, A., Freudenthaler, V., Linné, H., Ansmann, A., Bösenberg, J., D’ Amico, G., Mattis, I., Mona, L., Wandinger, U., Amiridis, V., AladosArboledas, L., Nicolae, D., and Wiegner, M.: EARLINET: towards an advanced sustainable European aerosol lidar network, Atmos. Meas. Tech., 7, 2389-2409, doi:10.5194/amt-7-23892014, 2014.

Quan, J., Gao, Y., Zhang, Q., Tie, X., Cao, J., Han, S., Meng, J., Chen, P., and Zhao, D.: Evolution of planetary boundary layer under different weather conditions, and its impact on aerosol concentrations, Particuology, 11, 34-40, doi:10.1016/j.partic.2012.04.005, 2013.

Russell, P. B., Uthe, E. E., Ludwig, F. L., and Shaw, N. A.: A comparison of atmospheric structure as observed with monostatic acoustic sounder and lidar techniques. J. Geophys. Res., 79, 5555-5566, 1974.

Scarino, A. J., Obland, M. D., Fast, J. D., Burton, S. P., Ferrare, R. A., Hostetler, C. A., Berg, L. K., Lefer, B., Haman, C., Hair, J. W., Rogers, R. R., Butler, C., Cook, A. L., and Harper, D. B.: Comparison of mixed layer heights from airborne high spectral resolution lidar, ground-based measurements, and the WRF-Chem model during CalNex and CARES, Atmos. Chem. Phys., 14, 5547-5560, doi:10.5194/acp-14-5547-2014, 2014.

Schäfer, K., Emeis, S., Hoffmann, H., and Jahn, C.: Influence of mixing layer height upon air pollution in urban and sub-urban area, Meteorol. Z., 15, 647-658, doi:10.1127/09412948/2006/0164, 2006.

Schneider, J. and Eixmann, R.: Three years of routine Raman lidar measurements of tropospheric aerosols: Backscattering, extinction, and residual layer height, Atmos. Chem. Phys., 2, 313-323, doi:10.5194/acp-2-313-2002, 2002.

Schween, J. H., Hirsikko, A., Löhnert, U., and Crewell, S.: Mixinglayer height retrieval with ceilometer and Doppler lidar: from case studies to long-term assessment, Atmos. Meas. Tech., 7, 3685-3704, doi:10.5194/amt-7-3685-2014, 2014.

Seibert, P., Beyrich, F., Gryning, S.-E., Joffre, S., Rasmussen, A., and Tercier, P.: Review and intercomparison of operational methods for the determination of the mixing height, Atmos. Environ., 34, 1001-1027, 2000.
Sicard, M., Pérez, C., Rocadenbosch, F., Baldasano, J. M., and Garcia-Vizcaino, D.: Mixed-Layer depth determination in the Barcelona coastal area from regular lidar measurements: Methods, results and limitations, Bound.-Lay. Meteorol., 119, 135157, 2006.

Sicard, M., D’Amico, G., Comerón, A., Mona, L., AladosArboledas, L., Amodeo, A., Baars, H., Baldasano, J. M., Belegante, L., Binietoglou, I., Bravo-Aranda, J. A., Fernández, A. J., Fréville, P., García-Vizcaíno, D., Giunta, A., Granados-Muñoz, M. J., Guerrero-Rascado, J. L., Hadjimitsis, D., Haefele, A., Hervo, M., Iarlori, M., Kokkalis, P., Lange, D., Mamouri, R. E., Mattis, I., Molero, F., Montoux, N., Muñoz, A., Muñoz Porcar, C., Navas-Guzmán, F., Nicolae, D., Nisantzi, A., Papagiannopoulos, N., Papayannis, A., Pereira, S., Preißler, J., Pujadas, M., Rizi, V., Rocadenbosch, F., Sellegri, K., Simeonov, V., Tsaknakis, G., Wagner, F., and Pappalardo, G.: EARLINET: potential operationality of a research network, Atmos. Meas. Tech., 8, 4587-4613, doi:10.5194/amt-8-4587-2015, 2015.

Song, T. and Wang, Y.: Carbon dioxide fluxes from an urban area in Beijing, Atmos. Res., 106, 139-149, doi:10.1016/j.atmosres.2011.12.001, 2012.

Song, T., Sun, Y., and Wang, Y.: Multilevel measurements of fluxes and turbulence over an urban landscape in Beijing, Tellus B, 65, 20421, doi:10.3402/tellusb.v65i0.20421, 2013.

Steyn, D. G., Baldi, M., and Hoff, R. M.: The detection of mixed layer depth and entrainment zone thickness from lidar backscatter profiles, J. Atmos. Ocean. Tech., 16, 953-959, 1999.

Strawbridge, K. B. and Snyder, B. J.: Planetary boundary layer height determination during Pacific 2001 using the advantage of a scanning lidar instrument, Atmos. Environ., 38, 5861-5871, doi:10.1016/j.atmosenv.2003.10.065, 2004.

Stull, R. B.: An Introduction to Boundary Layer Meteorology, Kluwer Academic Publishers, Dordrecht, 1988.

Sun, Y., Wang, Z., Fu, P., Jiang, Q., Yang, T., Li, J., and Ge, X.: The impact of relative humidity on aerosol composition and evolution processes during wintertime in Beijing, China, Atmos. Environ., 77, 927-934, doi:10.1016/j.atmosenv.2013.06.019, 2013.

Tang, G., Li, X., Wang, Y., Xin, J., and Ren, X.: Surface ozone trend details and interpretations in Beijing, 2001-2006, Atmos. Chem. Phys., 9, 8813-8823, doi:10.5194/acp-9-8813-2009, 2009.

Tang, G., Wang, Y., Li, X., Ji, D., Hsu, S., and Gao, X.: Spatialtemporal variations in surface ozone in Northern China as observed during 2009-2010 and possible implications for future air quality control strategies, Atmos. Chem. Phys., 12, 2757-2776, doi:10.5194/acp-12-2757-2012, 2012.

Tang, G., Zhu, X., Hu, B., Xin, J., Wang, L., Münkel, C., Mao, G., and Wang, Y.: Impact of emission controls on air quality in Beijing during APEC 2014: lidar ceilometer observations, Atmos. Chem. Phys., 15, 12667-12680, doi:10.5194/acp-1512667-2015, 2015.

Vogelezang, D. H. P. and Holtslag, A. A. M.: Evolution and model impacts of alternative boundary layer formulations, Bound.-Lay. Meteorol., 81, 245-269, 1996.

Wang, X. Y. and Wang, K. C.: Estimation of atmospheric mixing layer height from radiosonde data, Atmos. Meas. Tech., 7, 17011709, doi:10.5194/amt-7-1701-2014, 2014a.

Wang, Y. H., Hu, B., Ji, D. S., Liu, Z. R., Tang, G. Q., Xin, J. Y., Zhang, H. X., Song, T., Wang, L. L., Gao, W. K., Wang, X. K., 
and Wang, Y. S.: Ozone weekend effects in the Beijing-TianjinHebei metropolitan area, China, Atmos. Chem. Phys., 14, 24192429, doi:10.5194/acp-14-2419-2014, 2014b.

Wang, Z., Cao, X., Zhang, L., Notholt, J., Zhou, B., Liu, R., and Zhang, B.: Lidar measurement of planetary boundary layer height and comparison with microwave profiling radiometer observation, Atmos. Meas. Tech., 5, 1965-1972, doi:10.5194/amt5-1965-2012, 2012.

White, A. B., Senff, C. J., and Banta, R. M.: A Comparison of mixing depths observed by ground-based wind profilers and an airborne lidar, J. Atmos. Ocean. Tech., 16, 584-590, 1999.

Wiegner, M., Emeis, S., Freudenthaler, V., Heese, B., Junkermann, W., Münkel, C., Schäfer, K., Seefeldner, M., and Vogt, S.: Mixing layer height over Munich, Germany: variability and comparisons of different methodologies, J. Geophys. Res., 111, D13201, doi:10.1029/2005JD006593, 2006.

Wiegner, M.,Madonna, F, Binietoglou, I., Forkel, R., Gasteiger, J., Geiß, A., Pappalardo, G., Schäfer, K., and Thomas, W.: What is the benefit of ceilometers for aerosol remote sensing? An answer from EARLINET, Atmos. Meas. Tech., 7, 1979-1997, doi:10.5194/amt-7-1979-2014, 2014.

Xin, J., Wang, Y., Tang, G., Wang, L., Sun, Y., Wang, Y. H., Hu, B., Song, T., Ji, D. S., Wang, W. F., Li, L., and Liu, G. R.: Variability and reduction of atmospheric pollutants in Beijing and its surrounding area during the Beijing 2008 Olympic Games, Chinese Sci. Bull., 55, 1937-1944, 2010.

Yang, D. W., Li, C., Lau, A. K.-H., and Li, Y.: Long-term measurement of daytime atmospheric mixing layer height over Hong Kong, J. Geophys. Res., 118, 2422-2433, 2013.
Yang, H., Liu, W., Lu, Y., Xie, P., Xu, L., Zhao, X., Yu, T., and Yu, J.: PBL observations by lidar at Peking, Optical Tech., 31, 221-226, 2005.

Yang, Y. R., Liu, X. G., Qu, Y., An, J. L., Jiang, R., Zhang, Y. H., Sun, Y. L., Wu, Z. J., Zhang, F., Xu, W. Q., and Ma, Q. X.: Characteristics and formation mechanism of continuous hazes in China: a case study during the autumn of 2014 in the North China Plain, Atmos. Chem. Phys., 15, 8165-8178, doi:10.5194/acp-158165-2015, 2015.

Ye, X., Wu, B., and Zhang, H.: The turbulent structure and transport in fog layers observed over the Tianjin area, Atmos. Res., 153, 217-234, doi:10.1016/j.atmosres.2014.08.003, 2015.

Zhang, J. K., Sun, Y., Liu, Z. R., Ji, D. S., Hu, B., Liu, Q., and Wang, Y. S.: Characterization of submicron aerosols during a month of serious pollution in Beijing, 2013, Atmos. Chem. Phys., 14, 2887-2903, doi:10.5194/acp-14-2887-2014, 2014.

Zhang, Q., Quan, J., Tie, X., Li, X., Liu, Q., Gao, Y., and Zhao, D.: Effects of meteorology and secondary particle formation on visibility during heavy haze events in Beijing, China, Sci. Total Environ., 502, 578-584, doi:10.1016/j.scitotenv.2014.09.079, 2015.

Zhang, X., Cai, X., and Chai, F.: Structures and characteristics of the atmospheric boundary layer over Beijing area in autumn, Acta Sci. Natur. Univ. Pekinensis, 42, 220-225, 2006 (in Chinese).

Zilitinkevich, S. and Baklanov, A.: Calculation of the height of the stable boundary layer in practical applications, Bound.-Lay. Meteorol., 105, 389-409, 2002. 